\title{
Wnt/ $\beta$-catenin signalling in ovarian cancer: Insights into its hyperactivation and function in tumorigenesis
}

\author{
Vu Hong Loan Nguyen', Rebecca Hough', Stefanie Bernaudo ${ }^{1}$ and Chun Peng ${ }^{1,2^{*}}$ (D)
}

\begin{abstract}
Epithelial ovarian cancer (EOC) is the deadliest female malignancy. The Wnt/ $\beta$-catenin pathway plays critical roles in regulating embryonic development and physiological processes. This pathway is tightly regulated to ensure its proper activity. In the absence of Wnt ligands, $\beta$-catenin is degraded by a destruction complex. When the pathway is stimulated by a Wnt ligand, $\beta$-catenin dissociates from the destruction complex and translocates into the nucleus where it interacts with TCF/LEF transcription factors to regulate target gene expression. Aberrant activation of this pathway, which leads to the hyperactivity of $\beta$-catenin, has been reported in ovarian cancer. Specifically, mutations of CTNNB1, AXIN, or APC, have been observed in the endometrioid and mucinous subtypes of EOC. In addition, upregulation of the ligands, abnormal activation of the receptors or intracellular mediators, disruption of the $\beta$ catenin destruction complex, inhibition of the association of $\beta$-catenin/E-cadherin on the cell membrane, and aberrant promotion of the $\beta$-catenin/TCF transcriptional activity, have all been reported in EOC, especially in the high grade serous subtype. Furthermore, several non-coding RNAs have been shown to regulate EOC development, in part, through the modulation of $\mathrm{Wnt} / \beta$-catenin signalling. The $\mathrm{Wnt} / \beta$-catenin pathway has been reported to promote cancer stem cell self-renewal, metastasis, and chemoresistance in all subtypes of EOC. Emerging evidence also suggests that the pathway induces ovarian tumor angiogenesis and immune evasion. Taken together, these studies demonstrate that the Wnt/ $\beta$-catenin pathway plays critical roles in EOC development and is a strong candidate for the development of targeted therapies.
\end{abstract}

Keywords: Ovarian cancer, Wnt/ $\beta$-catenin signalling, microRNAs, cancer stem cells, metastasis, tumor angiogenesis

\section{Introduction}

Ovarian cancer is the most lethal gynecological malignancy and is ranked as the fifth leading cause of cancer deaths in females [1]. It is estimated that there are 22, 530 new cases with a mortality rate of approximately 13 , 980 deaths in the United States in 2019 [1]. Ovarian cancers are grouped into three categories based on the cell type of origin: epithelial, stromal, and germ cell cancer [2]. Among them, epithelial ovarian cancer (EOC) accounts for $90-95 \%$ of ovarian malignancies. EOC is further grouped into five histological subtypes: high-grade serous carcinomas (HGSC, 70\%-74\%), endometrioid carcinomas (EC, 7-24\%), clear cell carcinomas (CCC, 10\%-

\footnotetext{
*Correspondence: cpeng@yorku.ca

'Department of Biology, York University, Toronto, Ontario, Canada

${ }^{2}$ Centre for Research on Biomolecular Interactions, York University, Toronto, Ontario, Canada
}

26\%), low-grade serous carcinomas (LGSC, 3\%-5\%), and mucinous carcinomas (MC, 2\%-6\%) [3]. The poor survival rate of ovarian cancer patients is mainly due to the lack of screening methods at the early stages and the lack of effective treatments for advanced stages of the disease [4]. The standard chemotherapy for EOC patients is a combination of a platinum product, such as cisplatin or carboplatin, with a taxane, such as paclitaxel or docetaxel [3]. However, many patients develop resistance to these therapies and relapse [5, 6]. Recent research has introduced several therapeutic agents that target specific cancer-driven factors to inhibit ovarian cancer development. For example, bevacizumab, an antibody against vascular endothelial growth factor (VEGF)A, has been approved by the FDA to be used in combination with carboplatin and paclitaxel [7]. Moreover, several Poly (ADP-Ribose) Polymerase (PARP) inhibitors 
have been approved for the treatment of recurrent BRCA-mutated EOC [8].

The Wnt/ $\beta$-catenin pathway regulates cell proliferation, polarity, survival, and stem cell fate in embryonic and adult tissue homeostasis [9]. The pathway is tightly regulated to ensure its proper activity. It is well documented that aberrant Wnt signalling is associated with the development of several pathologies, including cancer $[10,11]$. Accumulating evidence shows that the Wnt/ $\beta$-catenin pathway regulates many key aspects of cancer development, including maintaining cancer stem cells (CSCs); promoting metastasis, cancer cell survival, and chemoresistance $[12,13]$; suppressing the immune response within the tumor microenvironment $[14,15]$; and enhancing tumor angiogenesis [16]. The role of the $\mathrm{Wnt} / \beta$-catenin pathway in CSC self-renewal, metastasis, and chemoresistance has been reported in all subtypes of EOC $[12,17]$. Recent studies suggest that this pathway is also involved in ovarian tumor angiogenesis [18] and immune evasion [19]. In addition, mutations that lead to the hyperactivity of $\beta$-catenin, are commonly observed in the EC subtype $[20,21]$. In this review, we will summarize current knowledge of the Wnt $/ \beta$-catenin signalling cascade, mutations and dysregulation in this pathway that result in the hyperactivation of $\beta$-catenin in EOC, and the involvement of this pathway in various aspects of EOC development.

\section{Overview of the Wnt/ $\beta$-catenin signalling pathway Wnt-off: inactivation and degradation of $\beta$-catenin}

$\beta$-catenin is the key mediator of the canonical Wnt pathway [9]. In the absence of a Wnt ligand, $\beta$-catenin is degraded by a destruction complex. The core components of this complex include AXIN, adenomatous polyposis coli (APC), casein kinase 1 (CK1), and glycogen synthase kinase $3 \beta$ (GSK3 $\beta$ ), as well as the E3 ligase, $\beta \operatorname{TrCP}$ (Fig. 1a). Protein phosphatase 2A (PP2A) is also associated with the $\beta$-catenin destruction complex. AXIN is a scaffolding protein that has interaction sites for multiple proteins including PP2A, APC, GSK3 3 , and CK1 [22]. Therefore, the presence of AXIN is essential for the assembly of the destruction complex. $\beta$-catenin is first phosphorylated by CK1 1 at the S45 and then by GSK3 $\beta$ at the S33, S37, and T41 [23, 24]. GSK3 $\beta$ also phosphorylates AXIN, stabilizing it and enhancing its interaction with $\beta$-catenin $[25,26]$. $\mathrm{APC}$, another core member of the destruction complex, contains multiple regions for AXIN and $\beta$-catenin interaction, enhancing $\beta$-catenin phosphorylation [22]. Finally, phosphorylated $\beta$-catenin is transferred to $\beta \operatorname{TrCP}$, which forms a complex with Skp1 and Cullin to facilitate the ubiquitylation and degradation of $\beta$-catenin [27].

\section{Wnt-on: activation of $\beta$-catenin}

$\beta$-catenin signalling is activated in the presence of Wnt ligands. On the cell surface, the binding of a Wnt ligand induces the heterogeneous dimerization of Frizzled (FZD) and LRP5/6 receptors, leading to their conformation change [9]. Dishevelled (DVL) is then recruited to the membrane through its interaction with the cytoplasmic domain of FZD [28]. Here, DVL binds AXIN and facilitates the recruitment of the destruction complex to the membrane. The association between the destruction complex and the membrane is further strengthened following phosphorylation of the cytoplasmic domain of LRP5/ 6 by kinases including CDK14, and GSK3 $\beta$ [29]. Consequently, the activities of the destruction complex in promoting $\beta$-catenin phosphorylation and degradation are inhibited. Unphosphorylated cytoplasmic $\beta$-catenin can then accumulate and translocate to the nucleus. Since $\beta$-catenin does not have DNA-binding domain, it activates transcription through the association with TCF/LEF members, histone modifiers such as CREBbinding proteins $(\mathrm{CBP})$, and other transcription factors [29]. Once inside the nucleus, $\beta$-catenin displaces the transcriptional repressor, Groucho, which forms a complex with TCF/LEF members in the absence of Wnt stimulation [13]. The active $\beta$-catenin/TCF complex can then initiate the transcription of its target genes [13] (Fig. 1b).

\section{Genetic alteration of the Wnt/ $\beta$-catenin pathway in ovarian cancer \\ $\beta$-Catenin}

The most common genetic alteration in the Wnt/ $\beta$-catenin pathway involved in EOC is in the $\beta$-catenin gene, CTNNB1 [21]. Mutations in this gene often result in an increased nuclear accumulation of $\beta$-catenin and, subsequently, an increase in transcription of its target genes [30]. This is most commonly observed in the EC subtypes, as one study found that activating mutations in CTNNB1 accounted for up to $54 \%$ of the EC cases [21]. In ECs that carried a missense mutation in CTNNB1, the mutation was always found within the aminoterminal domain [21]. Phosphorylation of this domain by GSK3 $\beta$ is required for degradation of $\beta$-catenin, and therefore, mutations within this domain would render $\beta$ catenin resistant to degradation. Indeed, mutations within the GSK3 $\beta$ phosphorylation domain were positively correlated with the nuclear localization of $\beta$ catenin and the level of $\beta$-catenin/TCF target genes [31].

\section{Destruction complex}

Mutations in several components of the destruction complex, such as AXIN, GSK3 $\beta$ and APC, have been reported in EOC. Since these proteins are important for the degradation of $\beta$-catenin, genetic alterations that render them less effective or non-functional are likely candidates for driving hyperactive $\beta$-catenin signalling and, as a result, oncogenesis. 

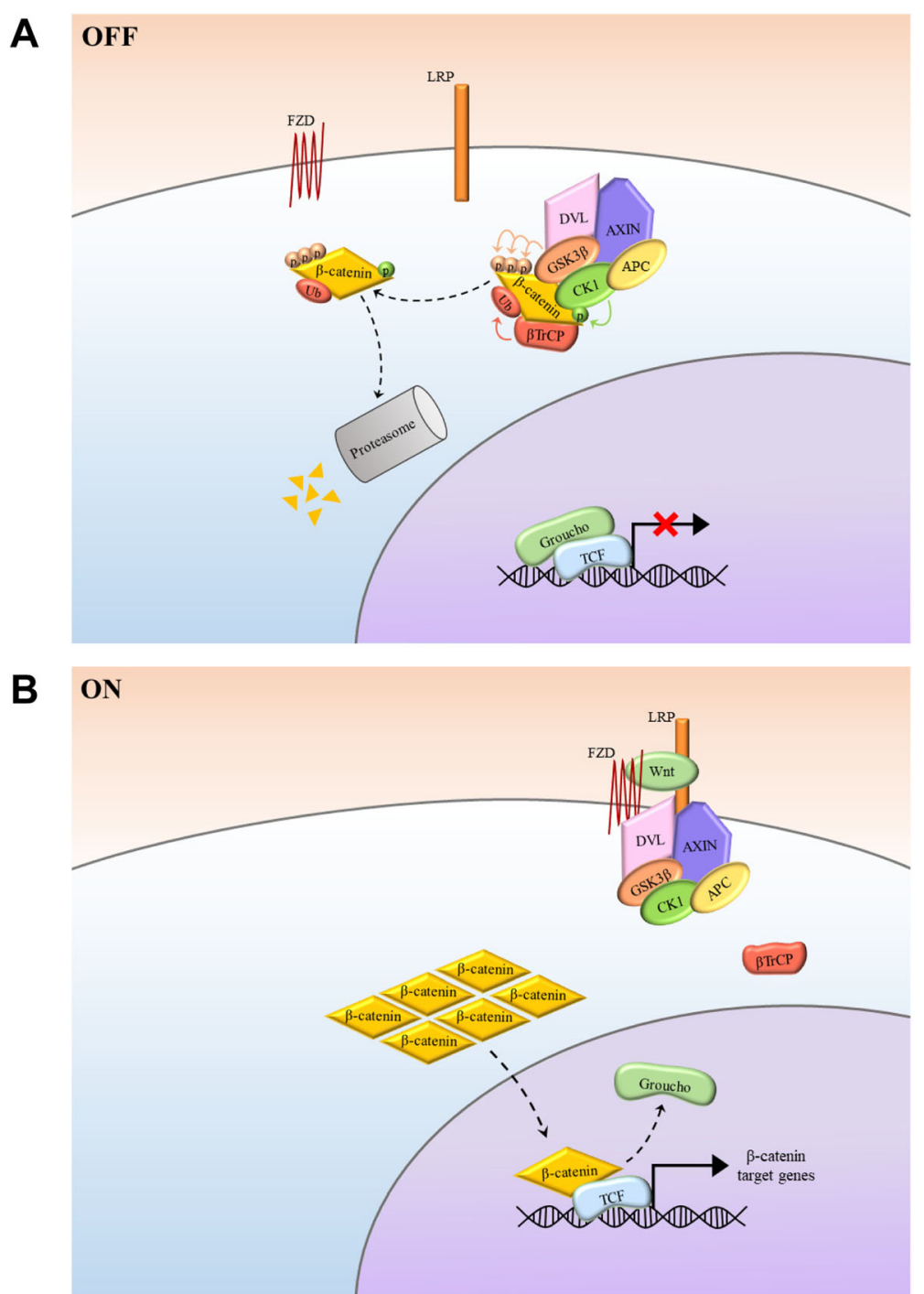

Fig. 1 The Wnt/ß-catenin signalling pathway. a Wnt signalling OFF. The absence of Wnt ligand binding to the FZD receptor prevents the interaction between FZD and LRP5/6. The destruction complex which resides in the cytoplasm binds to and promotes degradation of free cytoplasmic $\beta$-catenin. Specifically, CK1 and GSK-3 $\beta$ phosphorylate $\beta$-catenin, targeting it for $\beta \operatorname{TrCP}$-mediated ubiquitination and subsequent proteasome degradation. Within the nucleus, the transcriptional repressor, Groucho binds to TCF and inhibits its transcriptional activity. $\mathbf{b}$ Wnt signalling ON. Binding of a Wnt ligand to FZD and LRP5/6 promotes the recruitment of DVL and the destruction complex to the membrane. As a result, the destruction complex's ability to phosphorylate and degrade cytoplasmic $\beta$-catenin is inhibited. Cytoplasmic $\beta$-catenin accumulates and is translocated into the nucleus where it displaces Groucho and binds to TCF. Together with co-activators, the transcription of downstream target genes is initiated

Although much less common than mutations in $C T N N B 1$, mutations in the genes encoding AXIN and APC proteins ( $A X I N 1 / 2$ and $A P C$, respectively) have also been reported in EOC $[21,32]$. AXIN protein exists in two isoforms: AXIN1 and AXIN2. A nonsense mutation in AXIN1 has been found in one case of EC tumor, while a frameshift mutation in AXIN2 resulting in truncation has been found in another EC tumor [21]. Functional analyses indicated that the frameshift mutation altered AXIN2 function and promoted $\beta$-catenin/TCFdependent transcription [21].
Genetic alterations in APC, while frequently detected in colon cancers, are rarely found in EOC [11, 33]. As well, the involvement of $A P C$ mutations in EOC has been controversial. For instance, it was once believed that the $11307 \mathrm{~K}$ missense mutation in the $A P C$ gene conferred a modest increase in the risk of hereditary and sporadic breast/ovarian cancer development through its association with BRCA1/2 mutations. Later analysis, however, concluded that, although there exists a high prevalence of $11307 \mathrm{~K}$ mutation amongst BRCA1/2 carriers, the $11307 \mathrm{~K}$ allele confers no additional risk for 
cancer development [34]. Two missense mutations (K90N, S1400L) and one nonsense mutation (R1114) within the $A P C$ gene were identified in an MC tumor [35]. While the exact contributions made by these mutations were not examined in this study, the APC variants were suggested to be likely involved in MC development. More research is needed to determine the mechanism underlying $A P C$ mutations and the frequency at which these mutations occur in EOC.

\section{Dysregulation of $\mathrm{Wnt} / \mathrm{\beta}$-catenin signalling in ovarian cancer}

Although mutations in CTNNB1 and components of the $\beta$-catenin destruction complex are rare or restricted to only the EC and MC subtypes, higher $\beta$-catenin activity is often observed in EOC, especially in HGSC. The mechanisms underlying the hyperactivation of the Wnt/ $\beta$-catenin pathway in EOC are not entirely clear. However, many studies have reported the abnormal expression or activation of the components and regulators of this pathway. It is therefore highly possible that aberrant activities of these regulators contribute to the hyperactivation of Wnt/ $\beta$-catenin in EOC, as summarized in Fig. 2 and discussed below.

\section{Ligands and receptors}

Several Wnt ligands have been reported to be upregulated and associated with poor prognosis in EOC patients. For example, using immunohistochemistry, Wnt-5A expression was found to be strongly upregulated in EOC tumors when compared with benign epithelial neoplasia and normal ovarian samples and was negatively correlated with patient survival [30]. This study also found higher Wnt-1 immunoreactivity in EOC tumors but no significant association between Wnt-1 expression and patient survival [30]. Another study, which measured mRNA levels of all Wnt ligands in ovarian tumors, revealed that Wnt-7A and Wnt-7B were highly expressed, while Wnt-3 and Wnt-4 were reduced, in malignant ovarian tissues compared with normal ovarian tissues [36]. Subsequent analyses of Wnt7A by in situ hybridization confirmed that this upregulation occurred more frequently in serous than in EC, $\mathrm{MC}$, and CCC tumors [36]. Overexpression of Wnt-7A has also been identified in EC when compared to normal endometrium and benign endometrial lesions, and the immunoreactivity of Wnt7A in tumors was found to be negatively correlated with both overall and disease-free survival [37]. In vitro functional analysis showed that downregulation of Wnt-7A reduced ovarian cell proliferation, adhesion, invasion and expression of $\beta$-catenin target genes, suggesting an important role in the activation of Wnt/ $\beta$-catenin signalling and EOC development [36]. The significance of Wnt-5A, Wnt-1 and Wnt-7B upregulation and Wnt-3 and Wnt-4 downregulation in EOC remains to be determined. Similarly, the causes of aberrant Wnt expression in EOC remain unclear and require further investigation.

A recent study revealed that abnormal expression of $\mathrm{R}$-spondin 1 also contributes to the dysregulation of the Wnt/ $\beta$-catenin signalling pathway at the receptor level [38]. R-spondin 1 (encoded by RSPO1) belongs to the secreted R-spondin protein family, which bind to the LGR4, LGR5 or LGR6 receptors [39]. This binding inhibits the sequestration of FZD by the transmembrane E3 ligases, Rnf43 and Znrf3 [39], thereby enhancing $\beta$ catenin activity [40]. A genome-wide association study identified SNPs at RSPO1 as an EOC susceptibility locus [41]. RSPO1 was upregulated in all EOC cell lines and a small number of tissue samples when compared to normal ovarian tissue samples [38]. In HSGC subtype ovarian tumors, upregulation of RSPO1, RSPO2, LGR5 and LGR6 expression, although at low frequency, has also been observed [42]. Moreover, overexpression of RSPO1 increased EOC cell proliferation, migration, and chemoresistance [38]. Furthermore, overexpression of RSPO1 enhanced, whereas deletion of RSPO1 attenuated, $\beta$-catenin activity [38]. Similarly, silencing of LGR6 inhibited $\beta$-catenin activity [43]. These findings strongly support the role of RSPO1/LGR in enhancing Wnt/ $\beta$-catenin signalling and suggest that their upregulation during EOC development contributes to the hyperactive $\beta$-catenin signalling.

Wnt/ $\beta$-catenin signalling is tightly controlled by several negative regulators, some of which inhibit activation of Wnt signalling by competing with Wnt ligands for their receptors. Abnormal levels of these regulatory proteins have been associated with the dysregulation of Wnt/ $\beta$-catenin activity and EOC development. For example, Dickkopf (DKK) inhibits Wnt signalling by binding to LRP5/6 and disrupting the dimerization of FZD and LRP5/6 [44]. Interestingly, DKK1 was reported to be downregulated in EOC cells and negatively correlated with the stage of tumor development [45]. The expression of DKK2 was also significantly lower in EOC tumors than in normal ovary [46]. Secreted Frizzled-related proteins (SFRPs), similarly, interact with Wnt ligands and FZD receptors to abrogate their activations [44]. SFRP4 expression has been observed to be significantly downregulated in EOC cell lines and to be negatively correlated with the aggressiveness of EOC tumors and patient survival [47, 48]. In OVCAR3, a cell line with no detectable levels of SFRP4 [47], treatment with SFRP4 strongly inhibited $\beta$-catenin activity [49], indicating the important role of SFRP4 in suppressing $\beta$-catenin activity.

Downregulation of DKK2 in EOC tumors is believed to involve epigenetic silencing. Compared to benign tumors and normal ovarian tissues, DKK2 in EOC tumors was more commonly methylated and its methylation was 


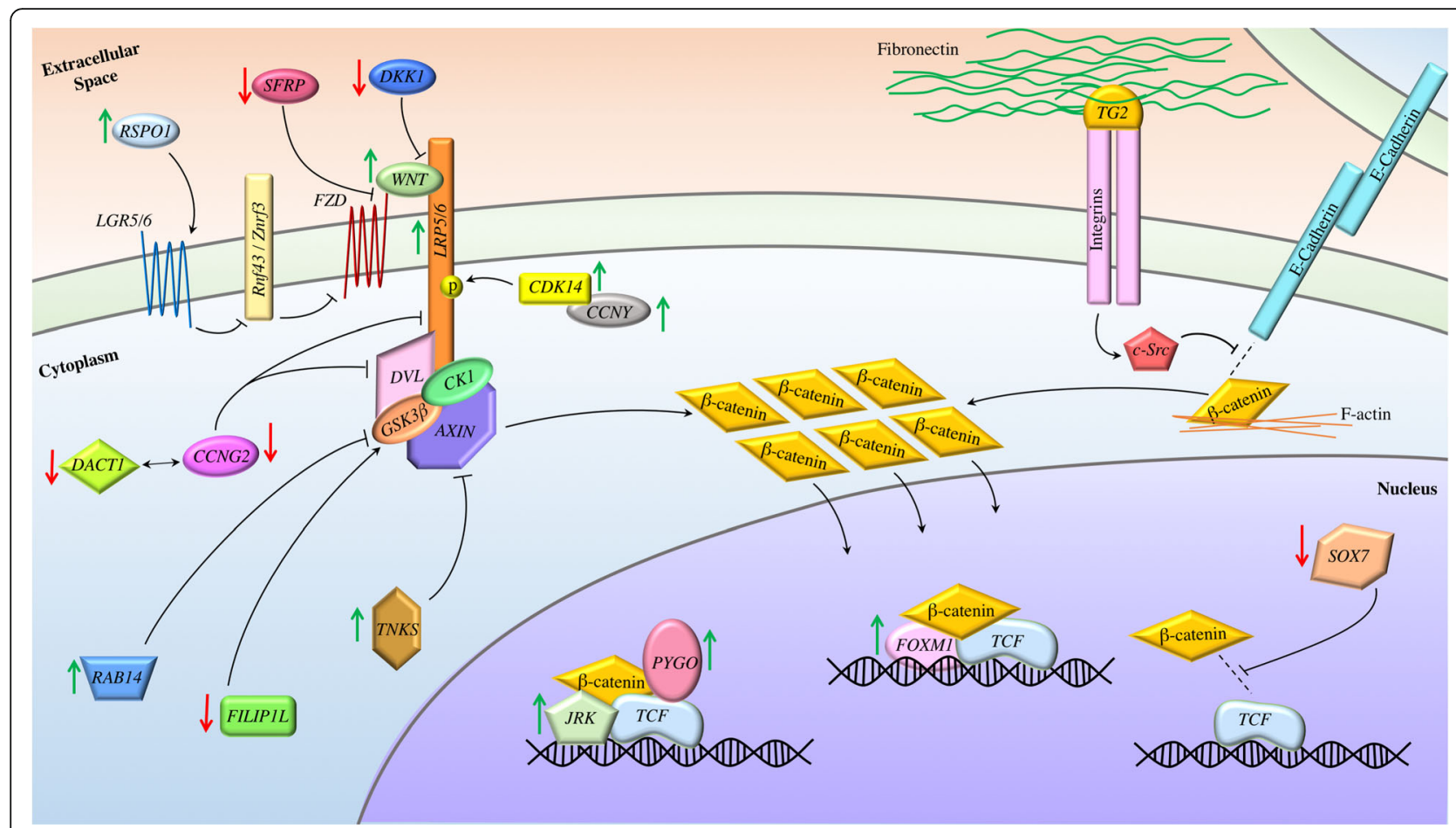

Fig. 2 Proposed mechanisms of Wnt/ $\beta$-catenin dysregulation in ovarian cancer. The Wnt/ $\beta$-catenin pathway is regulated by many factors, whose aberrant expression leads to the hyperactivation of $\beta$-catenin in the EOC. Note that green arrows indicate proteins whose expression is upregulated in EOC, while red arrows indicate downregulation. DKK1 and SFRP2, which inhibit the dimerization of FZD and LRP5/6 and directly prevent FZD activation, respectively, are downregulated in EOC tumors. In contrast, Wht ligands activate the pathway by forming a receptor complex with FZD and LRP5/6, while R-spondins bind LGRs and prevent the sequestration of the FZD. Both ligands and LGRs are overexpressed EOC. CCNY and CDK14 are also upregulated in EOC and have been suggested to work together to promote LRP5/6 phosphorylation and therefore activation. CCNG2, which is downregulated in EOC, decreases LPR6 and DVL levels. It may also interact with DACT1, also downregulated in EOC tumors, to promote DVL degradation. TNKS destabilizes AXIN to increase $\beta$-catenin activity and TNKS1 is known to be up-regulated in EOC. RAB14 inhibits the activity of GSK-3 $\beta$ and its upregulation contributes to higher $\beta$-catenin activity in EOC. FLIP1L, whose expression is negatively correlated with EOC progression, enhances GSK-3 $\beta$ activation in the destruction complex and is downregulated in EOC. This inhibition of the destruction complex results in the accumulation of $\beta$-catenin within the cytosol and its translocation into the nucleus. In addition, TG2, which is overexpressed in EOC, binds to integrin and fibronectin. This results in the recruitment of $\mathrm{c}$-Src and disruption of E-cadherin/ $\beta$-catenin complex on the membrane, which contributes to the accumulation of $\beta$-catenin within the cytoplasm. Finally, within the nucleus, higher expression of several co-activators of $\beta$-catenin/TCF, such as PYGO, JRK, and FOXM1, and lower expression of SOX7, which is known to inhibit the interaction between $\beta$-catenin and TCF, lead to the higher transcriptional activity of this complex

increased in higher grades and stages of EOC [46]. Similarly, decreases in DKK1 and SFRP2 levels in EOC have been suggested to be induced by DNA methylation [50]. TET1, a member of ten-eleven translocation (TET) family, was reported to promote the activation of DKK1 and SFRP2 expression in EOC [50]. TET1 plays an essential role in DNA demethylation by catalytically converting 5-methylcytosine to hydroxymethylcytosine, 5-formylcytosine and 5-carboxylcytosine [51]. Hypomethylation of the DKK1 and SFRP2 promoters was observed in EOC cells with ectopic TET1 expression [50]. Therefore, TET1 may bind to the CpG islands at the promoter regions of DKK1 and SFRP2, reducing the methylation levels and stimulating their expression by the transcriptional machinery. This is supported by the increase in DKK1 and SFRP2 levels observed in EOC cells with induced expression of TET1 and by undetectable levels of TET1 expression in several EOC cell lines [50]. Furthermore, the downregulation of TET1 is correlated with the clinical stage in EOC tissues [50].

Cyclin G2 (CCNG2) is an unconventional cyclin which has been shown to inhibit cell proliferation, migration and invasion in EOC cells $[52,53]$. CCNG2 was downregulated in EOC tissues compared to tumors with low malignant potential or normal ovarian tissues [53]. The inhibitory effects of cyclin G2 on EOC cell proliferation and invasion are mediated, at least in part, by the inhibition of $\beta$-catenin. Specifically, CCNG2 has been found to reduce LRP6, DVL2, and $\beta$-catenin levels in EOC [53]. While the mechanism by which CCNG2 inhibits LPR6 and DVL2 in EOC is not known, a recent report in gastric cancer indicated that CCNG2 downregulated DVL2 through the interaction with Dapper1 (DACT1) 
[54], a Wnt signalling antagonist that has been shown to promote DVL2 degradation [55]. Gao et al. revealed that there was a direct interaction between CCNG2 and DACT1 and that overexpression of DACT1 decreased DVL2 and $\beta$-catenin levels in gastric cancer cells [54]. While unphosphorylated DACT1 inhibited Wnt/ $\beta$-catenin pathway, its phosphorylated form promoted Wnt/ $\beta$-catenin signalling [56]. Remarkably, overexpression of CCNG2 inhibited phosphorylation of DACT1 by CK1, suggesting CCNG2 exhibits the inhibitory effects on canonical Wnt signalling by suppressing DACT1 phosphorylation through direct interaction and promoting DVL2 degradation by unphosphorylated DACT1 [54]. Recently, it was reported that DACT1 was downregulated in EOC samples derived from LGSC, EC, CC, and $\mathrm{MC}$, when compared with ovarian tissues collected from patients with benign gynecological disorders [57]. Thus, down-regulation of CCNG2 and DACT1 could contribute to the hyperactivation of the $\mathrm{Wnt} / \beta$-catenin pathway; however, whether or not there is an interaction between CCNG2 and DACT1 in EOC requires further investigation.

Another cell cycle regulator, cyclin Y (CCNY), also regulates $\beta$-catenin signalling. $\mathrm{CCNY}$ has been found to be upregulated in EOC tissues and its expression to be positively correlated with the clinicopathological stage [58]. In addition, the overexpression of CCNY increased cell proliferation, migration, and invasion, which was mediated by the $\mathrm{Wnt} / \beta$-catenin pathway. Ectopic expression of CCNY increased nuclear $\beta$-catenin levels and its transcriptional activity, leading to the upregulation of downstream target genes. A previous study indicated that cyclin $\mathrm{Y}$ and CDK14 could interact at the membrane to modulate LRP6 activation through phosphorylation [59]. Notably, the expression of CDK14 was also upregulated in clinical EOC samples and its expression was found to enhance the accumulation of nuclear $\beta$ catenin [60]. Therefore, the upregulation and association of cyclin $\mathrm{Y}$ and CDK14 in EOC may promote canonical Wnt signalling.

\section{The $\beta$-catenin destruction complex}

Decreases in the expression of certain components of the destruction complex are frequently observed in EOC [61]. For example, several studies have reported significantly higher methylation rates in the promoter region of $A P C$ in EOC tumors when compared to benign ovarian tumors or normal ovarian tissue samples [62-64]. However, the mechanisms underlying the hypermethylation and suppression of APC in EOC are not clear.

Tankyrases (TNKS), which belong to the poly (ADPribose) polymerase (PARP) family, are positive regulators of Wnt/ $\beta$-catenin signalling $[65,66]$. TNKS catalyzes ADP-ribosylation of AXIN and destabilize the protein.
Upregulation of TNKS1 expression was observed in EOC tissues and the immunoreactivity of TNKS1 was positively correlated with tumor size and stage [67]. Furthermore, inhibition or knockdown of TNKS1 reduced EOC cell proliferation, migration, invasion, and colony formation in vitro and tumor growth in nude mice, as well as aerobic glycolysis. Further studies confirmed that TNKS1 exerts these effects by promoting $\mathrm{Wnt} / \beta$-catenin signalling [67].

Inhibition of GSK3 $\beta$ has also been observed in EOC $[68,69]$. Initially, it was reported that GSK3 $\beta$ was overexpressed in EOC and was positively regulated the proliferation of ovarian cancer cells [61, 70]. However, further analyses revealed that GSK3 $\beta$ was frequently phosphorylated and thereby inactivated in EOC [12]. It was then postulated that GSK3 $\beta$ phosphorylation may be linked to the high frequency of activating mutations in PI3K in ovarian cancers [12]. The PI3K/AKT pathway is known to inhibit GSK3 $\beta$ activity through phosphorylation of S9 [71]. This increase in PI3K results in higher levels of active AKT, which in turn inactivates GSK3 $\beta$ and thus downregulates $\beta$-catenin signalling. In addition, Filamin A interacting protein 1-like (FILIP1L), which was reported to be down-regulated in EOC and negatively correlated with EOC tumor stages, chemoresistance, and patient survival [69], has been found to induce $\beta$-catenin degradation $[69,72]$. While the underlying mechanism by which FILIP1L inhibits $\beta$-catenin has not been determined in EOC, knockdown of FILIP1L in colon cancer cell lines led to an increase in phosphorylated AKT and GSK-3 $\beta$ and a decrease in phosphorylated $\beta$-catenin levels, suggesting that FILIP1L may promote $\beta$-catenin degradation by inhibiting AKT and thereby increasing GSK3 $\beta$ activity [73]. Finally, RAB14, a member of the RAS small G-protein superfamily $[68,74]$, has also been reported to be upregulated in EOC tissues and cell lines [68]. Overexpression of RAB14 increased GSK3 $\beta$ phosphorylation at S9 and enhanced $\beta$-catenin activity [68], suggesting that higher expression of RAB14 in EOC tumors contributes the hyperactivation of $\beta$-catenin by inhibiting GSK3 $\beta$ activity.

\section{Regulation of $\beta$-catenin subcellular localization}

$\beta$-catenin is a dynamic protein that can function as a component of adherens junctions or as a transcription factor depending on its subcellular localization. At the adherens junctions, $\beta$-catenin interacts with the cytoplasmic tail of E-cadherin and links E-cadherin to actin filaments through its interaction with $\alpha$-catenin to maintain the dynamics of the cytoskeleton [75, 76]. Dissociation of the adherens junctions results in the accumulation of $\beta$ catenin in the cytoplasm and its nuclear translocation to promote transcription of target genes [77]. The dissociation between $\beta$-catenin and E-cadherin is mediated by 
tyrosine phosphorylation at the C-terminal of $\beta$-catenin, decreasing its binding affinity to E-cadherin and $\alpha$-catenin [78]. In contrast, serine phosphorylation of E-catenin at its cytoplasmic tail increases the binding between E-cadherin and $\beta$-catenin [75], stabilizing the adherens junctions complex.

During EOC development, the membrane-associated $\beta$-catenin is dysregulated. Tissue transglutaminase 2 (TG2) has been shown to promote the dissociation of Ecadherin and $\beta$-catenin in EOC cells. TG2 was found to be overexpressed in EOC tumors and positively correlated with $\beta$-catenin levels in ovarian cancer cell lines $[79,80]$. TG2 forms a complex with fibronectin (FN) and $\beta 1$-integrin, enhancing the binding of FN to its cognate receptor and leading to the activation of c-Src. It has been proposed that, at the plasma membrane, activated c-Src phosphorylates $\beta$-catenin on Tyr 654, thereby inhibiting its interaction between E-cadherin [80]. Finally, activation of lysophosphatidic acid receptors (LPAR) by its ligand, lysophosphatitic acid (LPA) which is abundantly present in the ascites of EOC patients, also contributes to the loss of membrane $\beta$ catenin, probably by activating $\beta 1$-integrin and promoting the recruitment of E-catenin to the $\beta 1$-integrin clusters [81].

\section{Regulation of $\beta$-catenin in the nucleus}

Several proteins are believed to modulate $\beta$-catenin activity within the nucleus. SOX7, a member of the Sox transcription factor family, was demonstrated to suppress Wnt signalling in ovarian cancer cells harboring either wildtype or mutant $\beta$-catenin [82]. This was proposed to be accomplished through direct binding of SOX7 to $\beta$-catenin to disrupt its activity. Ectopic expression of SOX7 in TOV-112D cells significantly inhibited $\beta$-catenin transcriptional activity with downregulation of $\beta$-catenin/TCF target genes. Immunofluorescence and co-immunoprecipitation analysis indicated that SOX7 mainly localized in the nucleus where it interacted with $\beta$-catenin and TCF4 [82]. Furthermore, SOX7 expression was found to be significantly reduced in EOC tumors and negatively correlated with tumor progression [83]. Bioinformatics analyses predicted that another member of the Sox family, SOX17, would be involved in the development of ovarian cancer through its interaction with $\beta$-catenin [84]. However, this has not yet been proven experimentally.

Multiple proteins have been reported to form a complex with $\beta$-catenin and TCF/LEF and increase the stability of the transcriptional complex. Pygopus (PYGO) binds $\beta$-catenin directly in the nucleus and assists in transcription of its target genes [32]. PYGO2 has been detected in the all histological subtypes of EOC tumors and its expression was higher in EOC tissues than in benign ovarian tumors [85]. Suppression of PYGO2 inhibited cell proliferation, colony formation, and tumor growth, suggesting that it promotes ovarian cancer progression [85]. However, whether or not PYGO2 exerts these tumor-promoting effects by promoting $\beta$-catenin/ TCF activity requires further confirmation. In addition, JRK, which interacts directly with $\beta$-catenin through its $\mathrm{N}$-terminal, stabilizes the transcriptional complex consisting of $\beta$-catenin, LEF1, and PYGO2 [86, 87]. Mining the TCGA database revealed copy-number gains in JRK and higher JRK mRNA levels in some serous tumors [87]. Furthermore, knockdown or deletion of the Nterminal of JRK decreased the activity of $\beta$-catenin, downregulated $\beta$-catenin target genes, and inhibited cell proliferation [87]. These findings suggest that JRK promotes EOC development by enhancing $\beta$-catenin activity.

FOXM1, a member of forkhead transcription factors, plays important roles in EOC development in part by regulating $\beta$-catenin signalling. High FOXM1 levels were found to be correlated with EOC tumor grade and stage, and to predict poor prognosis and chemoresistance [88-91]. Interestingly, high FOXM1 immunoreactivity was significantly associated with high $\beta$-catenin staining [92]. FOXM1 has been shown to induce $\beta$-catenin transcription in EOC cells [91, 92]. In addition, FOXM1 has also been reported to promote $\beta$-catenin nuclear translocation and to form a complex with $\beta$ catenin and TCF4 to induce target gene expression in glioma cells [93]. On the other hand, activation of Wnt/ $\beta$-catenin signalling also increased mRNA and protein levels of FOXM1 [91]. The findings suggest that FOXM1 and $\beta$-catenin form a positive feedback loop that contributes to EOC development.

\section{Role of non-coding RNAs in regulating the $\beta$-catenin activity}

Non-coding RNAs are RNA transcripts that do not encode proteins [94-96]. However, they are important regulatory molecules that modulate cellular processes by controlling gene expression. There are three major types of regulatory non-coding RNAs: long non-coding RNA (lncRNAs), microRNAs (miRNAs) and circular RNAs (circRNAs). IncRNAs are transcripts which have the length greater than 200 nucleotides while miRNAs are transcripts with 30 nucleotides or shorter [94, 95]. lncRNAs exhibit a broad range of mechanisms in mediating transcriptional repression or activation due to interactions with both RNAs and proteins [94]. In contrast, miRNAs suppress gene expression primarily through complementary binding to their target mRNAs, inhibiting their translational activity and reducing the stability of the target transcripts [96]. circRNAs are generated through the process of back splicing and function 
as miRNA sponges and protein scaffolds to regulate gene expression [97]. Aberrant expression of non-coding RNAs is implicated in ovarian tumorigenesis.

Multiple studies have shown the involvement of non-coding RNAs in EOC progression through the modulation of the $\mathrm{Wnt} / \beta$-catenin pathway (summarized in Tables 1 and 2). Dysregulation of miRNAs promotes EOC pathology in many ways including proliferation, metastasis, and chemoresistance [95]. For example, miR-92a, miR-939, and miR-1207 were upregulated in EOC and promoted Wnt/ $\beta$-catenin signalling via direct repression of Wnt inhibitors including DKK1, APC2, SFRP1, AXIN2 and ICAT [100, 103, 104]. Similarly, miR-126-5p targeted negative regulators of the Wnt/ $\beta$-catenin pathway, namely DKK3 and AXIN1 [99]. In contrast, miRNAs such as miR-15b and miR-219-5p, which regulate the expression of various Wnt components including Wnt7A and Twist, have been reported to be downregulated in EOC, allowing the upregulation of Wnt signalling at various levels $[111,116]$.

In addition to modulating the expression of key components of the $\mathrm{Wnt} / \beta$-catenin pathway, many miRNAs have been reported to inhibit regulators of this pathway. Recently, we demonstrated that miR-590-3p levels were upregulated in EOC tissues when compared to normal ovarian tissue and EOC tumors with low malignancy potential [126]. miR-590-5p enhanced cell proliferation, invasion and migration in vitro, and promoted tumor formation and metastasis in vivo [127]. We showed that miR-590-3p targeted CCNG2 and FOXO3, a transcription factor that induces CCNG2 transcription in EOC, and enhanced $\beta$-catenin activity $[127,128]$. Silencing of CTNNB1 attenuated the effect of miR-590-3p-induced formation of compact spheroids, indicating that miR590-3p promotes EOC development in part via the activation of $\mathrm{Wnt} / \beta$-catenin signalling [127]. Several other miRNAs that modulate the activity of $\beta$-catenin, are also dysregulated in EOC. It was reported that miR-340 was down-regulated in EOC and exerted anti-tumor effects by targeting four and a half LIM domain protein 2 (FHL2), a co-activator of $\beta$-catenin [106]. Another study reported that miR-762 promoted EOC cell proliferation, migration, and invasion by upregulating $\mathrm{Wnt} / \beta$-catenin signalling via suppression of menin [101], which has been reported to promote $\beta$-catenin cytoplasmic shuttling and degradation $[129,130]$. Finally, miR-377, miR101, miR-381, and miR-429 were found to target Cullin E3-Ring E3-ligase family member, CUL4A, membraneassociated E3 ubiquitin ligase MARCH7, transcription factor Ying Yang 1 (YY1), and the PNCA-associated

Table 1 Regulation of the Wnt/B-catenin signaling pathway by miRNAs in EOC

\begin{tabular}{|c|c|c|c|c|c|}
\hline miRNA & Targets & Expression in EOC & Effects on EOC & $\begin{array}{l}\text { Effects on } \beta \text {-catenin } \\
\text { activity }\end{array}$ & Reference \\
\hline miR-27a & FOXO1 & Increased & Promote EMT in ovarian cancer & Activate & [98] \\
\hline miR-126-5p & AXIN1, DKK3 & N.D & Promote platinum resistance & Activate & [99] \\
\hline miR-92a & DKK1 & Increased & Promote stemness and chemoresistance & Activate & [100] \\
\hline miR-762 & MEN1 & Increased & $\begin{array}{l}\text { Promote proliferation, migration and invasion } \\
\text { and inhibit apoptosis }\end{array}$ & Activate & [101] \\
\hline miR-197 & NLK & Increased & Promote taxol resistance & Activate & [102] \\
\hline miR-939 & $A P C 2$ & Increased & $\begin{array}{l}\text { Promote proliferation and anchorage-independent } \\
\text { growth }\end{array}$ & Activate & [103] \\
\hline miR-1207 & SFRPI, AXIN2, ICAT & Increased & Promote cancer stem-like trait & Activate & [104] \\
\hline miR-16 & ND & Decreased & Inhibit proliferation, migration and invasion & Suppress & [105] \\
\hline miR-340 & FHL2 & Decreased & Inhibit proliferation and metastasis & Suppress & [106] \\
\hline $\operatorname{miR}-34 \mathrm{c}$ & soxg & Decreased & Inhibit proliferation and cisplatin chemoresistance & Suppress & [107] \\
\hline miR-377 & CUL4A & Decreased & Inhibit cell proliferation & Suppress & [108] \\
\hline miR-370 & FOXM1 & Decreased & Inhibit proliferation and metastasis & Suppress & [109] \\
\hline miR-214 & ND & Decreased & Inhibit proliferation and invasion & Suppress & [110] \\
\hline miR-219-5p & TWIST1 & Decreased & Inhibit proliferation, migration, and invasion & Suppress & [111] \\
\hline miR-152 & WNT1, ADAM17 & Decreased & Inhibit EMT, migration, and invasion & Suppress & [112] \\
\hline miR-133a-3p & ND & Decreased & Inhibit proliferation and invasion & Suppress & [113] \\
\hline miR-429 & KIAA0101 & Decreased & Inhibit cell migration, invasion and cisplatin resistance & Suppress & [114] \\
\hline miR-381 & YY1 & Decreased & Inhibit proliferation and migration & Suppress & [115] \\
\hline miR-15b & WNT7A & Decreased & Decrease adhesion and invasion & Suppress & [116] \\
\hline miR-101 & MARCH7, ZEB1, ZEB2 & Decreased & Inhibit proliferation, migration, and invasion & Suppress & [117-119] \\
\hline
\end{tabular}


Table 2 Wnt/ $\beta$-catenin pathway-associated long noncoding RNAs in EOC

\begin{tabular}{|c|c|c|c|c|c|}
\hline & Targets & Expression in EOC & Effects on EOC & $\begin{array}{l}\text { Effects on } \beta \text {-catenin } \\
\text { activity }\end{array}$ & Reference \\
\hline \multicolumn{6}{|c|}{ Long noncoding RNAs } \\
\hline CCAT2 & $N D^{*}$ & Increased & Promote EMT & Activate & [120] \\
\hline SNHG20 & Inactivate GSK3b & Increased & Promote proliferation and inhibit apoptosis & Activate & [121] \\
\hline MALAT1 & $\begin{array}{l}\text { Increase DVL2 and } \\
\beta \text {-catenin }\end{array}$ & Increased & Promote proliferation, migration and inhibit apoptosis & Activate & [122] \\
\hline Linc-ROR & ND & Increased & $\begin{array}{l}\text { Promote proliferation, migration and invasion } \\
\text { through EMT }\end{array}$ & Activate & [123] \\
\hline HOTAIR & ND & Increased & Promote proliferation and chemoresistance & Activate & [124] \\
\hline HOXD-AS1 & $\begin{array}{l}\text { miR-133a-3p, } \\
\text { miR-186-5p }\end{array}$ & Increased & Promote cell proliferation and invasion & Activate & [113] \\
\hline \multicolumn{6}{|l|}{ circRNAs } \\
\hline Circ-ITCH & miR-145 & Decreased & Inhibit OC cells proliferation, migration and invasion & Suppress & [125] \\
\hline Circ_0061140 & miR-370 & Increased & Promote cell proliferation and migration & Activate & [109] \\
\hline
\end{tabular}

${ }^{*} \mathrm{ND}$, not determined

factor, KIAA0101, respectively, in EOC [108, 114, 115, 117]. Ectopic expression of CUL4A, MARCH7, YY1, and KIAA0101 promoted $\beta$-catenin nuclear translocation and downstream target gene expression. However, whether there is a direct interaction between CUL4A, MARCH7, YY1, KIAA0101 and central Wnt regulators in EOC remains to be elucidated.

Several lncRNAs have been reported to be upregulated in EOC, activate $\beta$-catenin signalling, and promote EOC development (Table 2). However, little is known about how these lncRNAs promote $\beta$-catenin signalling. For example, HOXD-AS1 has been found to upregulate $\beta$ catenin by down-regulating two miRNAs that target the Wnt/ $\beta$-catenin pathway. HOXD-AS1 was overexpressed in EOC tumors and negatively correlated with patient survival [131]. HOXD-AS1 was found to directly bind to miR-186-5p, which targeted PIK3R3, a regulatory subunit of PI3K [131]. Although the consequence of miR186-5p inactivation by HOXD-AS1 on $\beta$-catenin has not been determined in EOC cells, it was reported that miR186-5p enhanced AKT phosphorylation and $\beta$-catenin levels in prostate cancer cells [132]. HOXD-AS1 was also reported to target $\mathrm{miR}-133 \mathrm{a}-3 \mathrm{p}$ and to increase Wnt/ $\beta$-catenin signalling [113]. However, it is unclear if and how these two events are related. It has been reported that SNHG20 induced GSK3 $\beta$ inactivation [121], whereas MALAT1 increased DVL2 and $\beta$-catenin levels [122]; however, the underlying mechanisms of their actions are still elusive.

While modulation of $\beta$-catenin signalling by circRNAs has been reported in other types of cancer [133-136], there are currently no direct evidence that circRNAs affect EOC development through regulation of the Wnt/ $\beta$-catenin pathway. However, a recent study has shown that circ_0061140 exerts tumor-promoting effects by sponging miR-370, which targets FOXM1 [109]. Since FOXM1 enhances $\beta$-catenin signalling $[91,93]$, it is possible that circ_0061140 would also increase the activity of $\beta$-catenin. In addition, downregulation of circ-ITCH has been observed in EOC tissues [125]. It has been reported in colorectal and lung cancer that overexpression of circ-ITCH inhibited $\beta$-catenin expression and its transcriptional activity, suppressing cancer cell proliferation $[137,138]$. Mechanistically, circ-ITCH sponged miR-22$3 p$ to regulate CBL levels in thyroid cancer cells [139]. CBL is a unique E3 ligase that can translocate into the nucleus with $\beta$-catenin and modulate nuclear $\beta$-catenin degradation in the Wnt-on phase [139]. Therefore, there is an association between circ-ITCH and Wnt/ $\beta$-catenin in carcinogenesis, but whether or not this occurs in EOC remains to be investigated.

\section{Role of Wnt/ $\beta$-catenin in ovarian cancer development}

It is well established that the $\mathrm{Wnt} / \beta$-catenin pathway exerts tumor-promoting effects in EOC [12, 94, 95]. This pathway has been shown to promote cell proliferation, survival migration, and invasion, maintain cancer stem cells, induce resistance to therapeutic agents, and may also be involved in the tumor angiogenesis [18] and immune suppression [19].

\section{Stemness}

It is now widely accepted that tumors are made up of a heterogeneous population of cancer cells, a small portion of which is characterized as cancer stem cells (CSCs) [140]. Like normal stem cells, CSCs possess self-renewal and differentiation potential that contribute to the heterogeneity of cancer cell populations. CSCs have high tumorigenic potential and play major roles in driving tumor initiation, metastasis, chemoresistance, and cancer 
recurrence [140]. Ovarian CSCs have been characterized by functional and phenotypic expression of surface markers such as CD24, CD44, CD117, ALDH, CD133, SOX2, NANOG, OCT4 and EPCAM [91, 104, 141, 142]. Ovarian tumor-isolated mesenchymal stem cells were identified to exhibit high levels of CD133 and ALDH expression [143]. Additionally, the increase in stem cell marker expression in ovarian CSCs was detected together with the ability to form spheroids in vitro and tumors in vivo, contributing to the initiation and progression of EOC [91, 100, 104, 143]. These cells are more resistant to chemotherapy and capable of giving rise to progenitor tumor cells, leading to tumor progression, metastasis, and recurrence [144-149].

Accumulating evidence points toward the Wnt/ $\beta$-catenin pathway in playing an important role in the acquisition of stem-like properties in ovarian cancer cells [91, 104, 150]. Among stem cell markers, ALDH1A1 has been found to be a direct transcriptional target of $\beta$-catenin [151]. In addition, silencing of $\beta$-catenin strongly reduced the stem-like properties $[17,151]$. These findings provide direct evidence that $\beta$-catenin is involved in promoting EOC stemness.

Several studies have found that modulation of $\beta$ catenin activity altered the CSC-like properties. For example, miR-1207 suppressed SFRP1, AXIN2, and ICAT, three important negative regulators of the $\mathrm{Wnt} / \beta$-catenin signalling pathway, to activate $\beta$-catenin signalling and promote the expression of CSC markers [104]. Likewise, Wnt positive regulators LGR5 and LGR6 have been recognized as markers for ovarian cancer stem cells $[43,152,153]$. The high expression of LGR5 and LGR6 was positively correlated with poor patient survival and was observed predominantly in high-grade tumors [43, 152]. Silencing of LGR6 significantly inhibited stemness and the effects of LGR6 were demonstrated to be mediated by the $\beta$-catenin activity [43]. Finally, several $\beta$ catenin inhibitors were documented to exert inhibitory effects on ovarian CSCs. Theaflavin-3, 3'-digallate (TF3), a black tea polyphenol, was found to inhibit EOC stemness by blocking Wnt/ $\beta$-catenin signalling [154]. Ginsenoside$\mathrm{Rb} 1$, a natural saponin isolated from the rhizome of Panax quinquefolius and notoginseng, and its metabolite, compound $\mathrm{K}$, suppressed CSC self-renewal and inhibited $\beta$ catenin activity [155]. Together, these studies strongly support the critical role of the $\mathrm{Wnt} / \beta$-catenin pathway in maintaining stemness in EOC.

\section{Chemoresistance}

Recent studies encompassing ovarian CSCs and their involvement in EOC tumorigenesis reveal the association of CSCs and chemoresistance [91, 100, 156, 157]. There is a high correlation between nuclear $\beta$-catenin levels/activities and chemoresistance of stem-like EOC cells.
$\mathrm{ALDH}^{+} / \mathrm{CD} 44^{+}$ovarian CSCs exhibited higher levels of resistance to paclitaxel and carboplatin [157]. Additionally, an increase in cisplatin and paclitaxel resistance was observed in IGROV1 sublines and was associated with elongated mesenchymal-like morphology and a decrease in cell-cell interactions [91]. Since CSCs are linked to chemoresistance, many of the studies described above also reported the chemosensitizing effects of $\beta$-catenin silencing [158] or inhibition [38, 67, 91] on EOC cells.

One of the mechanisms for chemoresistance in CSCs is the deregulation of membrane transporters, such as an ATP-binding cassette (ABC) transporter, ABCG2 [91, 104, 159]. The study by Chau et al. (2013) identified the involvement of c-kit (also known as CD177), a stem cell-associated receptor tyrosine kinase, in promoting ovarian stem-like phenotypes and chemoresistance via the $\mathrm{Wnt} / \beta$-catenin/ABCG2 axis [159]. c-kit and SCF were upregulated in ovarian tumor-initiating cells. Knockdown of c-kit reduced the numbers of spheroids formed in vitro and rendered the cells more susceptible to chemotherapeutic reagents, including cisplatin and paclitaxel [159]. In addition, increased c-kit transcriptional level led to an increase in Wnt/B-catenin signalling pathway and mRNA levels of ABCG2 transporter, which promoted the efflux of chemotherapeutic drugs as the results [159]. Besides, Wnt/ $\beta$-catenin pathway was reported to indirectly modulate the expression of human copper transporter 1 (hCRT1) via FOXM1 [91]. hCRT1 is a transmembrane transporter that allows the passage of copper and cisplatin through the membrane barrier into cells [91]. In cisplatin-resistant EOC cells, upregulation of FOXM1 inhibited the expression of human copper transporter 1 (hCTR1) and SP1, a transcription factor that induces hCTR1 expression [91]. It has been demonstrated that FOXM1 promotes $\beta$-catenin nuclear localization while $\beta$-catenin activation promotes FOXM1 expression as a positive feedback loop [91, 93]. In response to Wnt-3A, FOXM1 expression was upregulated in TOV$21 \mathrm{G}$ cells in a dose-dependent manner [91]. Thus, induced expression of FOXM1 by Wnt $/ \beta$-catenin signalling would impair cisplatin uptake in EOC cells.

In addition to promoting resistance to conventional chemotherapies, a recent study provided evidence to support the activation of the Wnt/ $\beta$-catenin signalling in inducing resistance to a PARP inhibitor, olaparib [160]. Activators and target genes of the $\mathrm{Wnt} / \mathrm{\beta}$-catenin pathway were found to be induced, while inhibitors of this pathway were suppressed in olaparib-resistant HGSC cell lines. Overexpression of Wnt-3A reduced the sensitivity of EOC cells to olaparib. Conversely, inhibition of Wnt/ $\mathrm{B}$-catenin signalling enhanced the anti-tumor effects of olaparib both in vitro and in vivo [160]. These results and studies discussed above support the potential of Wnt/B-catenin inhibitors for the management of EOC patients with drug resistance. 


\section{EMT and metastasis}

Epithelial to mesenchymal transition (EMT) is a cellular process in which epithelial cells lose cell-cell adhesion and acquire mesenchymal characteristics, including migration and invasion [161]. The attainment of invasiveness allows cells to break through the basement membrane, which eventually results in metastasis in ovarian cancer [12, 161]. Many studies examining invasive characteristics of ovarian cancer suggest that activation of EMT is a critical step in acquiring malignant phenotypes, especially in high-grade serous ovarian carcinoma [162, 163].

Recent evidence indicates that the activity and expression levels of E-cadherin and $\beta$-catenin are critical in the initiation of EMT in ovarian cancer cells [162]. Loss of E-cadherin has been observed in ovarian cancer cell lines with increased invasion and migration phenotypes $[123,164]$. E-cadherin assists in keeping a low cytosolic/nuclear $\beta$-catenin level by forming a complex with $\beta$-catenin at the adherens junctions and, therefore, the decrease in E-cadherin would involve in the promotion of $\beta$-catenin signalling. The accumulation of nuclear $\beta$-catenin levels was detected together with decreased levels of E-cadherin and increased cancer cell motility $[113,164]$. Moreover, the Wnt/ $\beta$-catenin pathway modulates the expression of E-cadherin through upregulation of key transcription factors, whether directly or indirectly. These transcription factors are known as mesenchymal inducers, and include Twist, Snail and Slug $[98,105,113,130,163,165,166]$. Twist, Snail and Slug bind to specific E-boxes located proximal to the Ecadherin promoter and suppress its expression [167]. In addition, Snail can form a transcriptional complex with $\beta$ catenin, providing a positive regulatory feedback to enhance its own expression through the transcriptional activity of $\beta$-catenin $[167,168]$.

Additionally, Wnt/ $\beta$-catenin signalling is involved in the remodeling of the extracellular tumor matrix in EOC, which is suggested to be mediated by the activities of matrix metallopeptidases (MMP). MMPs are proteolytic enzymes that act on diverse extracellular matrix (ECM) components such as fibronectin, gelatins, collagens, and laminins [169]. MMP-2, MMP-7, and MMP-9 have all been shown to be upregulated in Wnt-activated cells and were reported as direct transcriptional targets of $\beta$-catenin [36, 101, 123, 170]. Dysregulation of these MMPs was frequently observed in EOC [171-173]. MMP-9 [174] and MMP-2 [164] promoted invasion and metastasis while MMP-7 was reported to activate MMP2 and MMP-9 in vitro [175]. Furthermore, increased $\beta$ catenin levels have been detected in tumor samples from orthotopic xenograft mice implanted with high metastatic EOC cells [176]. Silencing of $\beta$-catenin displayed a significant reduction in the ability to form primary tumors and ascites in the mouse model, providing direct evidence for an essential role of $\beta$-catenin in EOC metastasis [176].

\section{Tumor angiogenesis}

Tumor angiogenesis, wherein tumors promote blood vessel formation to provide themselves with nutrients and oxygen, is one of the hallmarks of cancer [16]. Multiple steps are involved in angiogenesis including vasculature disruption, cell migration, cell proliferation, and vessel formation [177]. While studies in other cancers have provided strong evidence that the $\mathrm{Wnt} / \beta$-catenin pathway is an important player in tumor angiogenesis $[16,178]$, very few studies have been done in EOC. A recent study by Tang et al. (2018) examined the role of soluble E-cadherin in EOC and revealed that it interacted with VE-cadherin to induce angiogenesis [18]. Interestingly, soluble E-cadherin containing exosomes induced strong $\beta$-catenin accumulation in the nucleus. Importantly, silencing of $\beta$-catenin expression attenuated the effect of soluble E-cadherin containing exosomes on the formation of network-like structure [18]. These findings suggest that $\beta$-catenin may induce tumor angiogenesis. However, more studies, especially involving in vivo mouse models, is required to confirm the role of $\beta$ catenin in ovarian tumor angiogenesis.

\section{Immune suppression}

Ovarian cancer has been reported to evade the immune system using multiple mechanisms, including the recruitment of regulatory $\mathrm{T}$ cells (Treg) and the promotion of $\mathrm{T}$ cell apoptosis via PD-L1 $[179,180]$. The presence of Treg in ovarian tumors increases immune tolerance and is correlated with poor patient prognosis [179]. In addition, IL-10 and indoleamine 2, 3-dioxygenase (IDO) were reported to promote immune evasion by ovarian tumor-associated macrophages [181]. Notably, expression of IDO is associated with poor prognosis in ovarian cancer [182, 183]. In the presence of ovarian tumor ascites $\mathrm{CD} 4^{+}$cells, which expressed IDO and IL-10, CD4 ${ }^{+} \mathrm{T}$ cells showed inhibition in responsiveness to antigen stimulation, suggesting IDO and IL-10 might be involved in the regulation of the immune response in EOC [181]. The same study suggests that IDO may induce Treg differentiation and apoptosis of T-cells, regulating the balance of Treg and effector T cells Th17. IDO promoter contains TCF/LEF binding domains, which was reported to be activated by Wnt $/ \beta$-catenin signaling [184]. However, there is no direct evidence indicating the $\mathrm{Wnt} / \beta$-catenin pathway promotes immune evasion of EOC cells.

\section{Conclusion and future perspectives}

Aberrant Wnt/ $\beta$-catenin signalling has been widely linked to cancer development. Increasing evidence 
indicates that this pathway is hyperactivated in EOC and plays important roles in driving EOC development. Although mutations of CTNNB1, APC, and AXINs are restricted to the EC and MC subtypes of the EOC, hyperactivation of $\beta$-catenin is commonly observed in HGSC tumors and involves diverse mechanisms. This could be due to overexpression of ligands and receptors, underexpression of inhibitors of the $\mathrm{Wnt} / \beta$-catenin pathway, and altered expression of proteins that regulate $\beta$-catenin/E-cadherin interaction on the membrane or $\beta$ catenin/TCF transcriptional activity, as summarized in Fig. 2. In addition, many non-coding RNAs, particularly miRNAs, have been shown to modulate this pathway, directly and indirectly, to exert their oncogenic or antitumor effects on EOC. The role of circRNAs in EOC development is emerging; however, little is known about how circRNAs modulate $\beta$-catenin signalling in EOC.

Compared to other types of cancer, especially colon cancer, fewer studies have been done on EOC to investigate the roles and mechanisms of the $\mathrm{Wnt} / \beta$-catenin signalling pathway in the process of tumorigenesis. Nevertheless, evidence accumulated to date strongly supports a critical role for this pathway in promoting several key aspects of EOC development, from promoting CSC self-renewal, EMT and metastasis, drug resistance, and tumor angiogenesis, to suppressing tumor immunity. However, many of these studies were carried out using established cell lines and some of them were only conducted in vitro. Therefore, it is important to confirm key findings in primary tumor cells collected from patients. Furthermore, EOC is composed of different histologic subtypes, each with distinct molecular features, mutational profiles, and even cellular origins [3]. While the tumor-promoting effects of $\beta$-catenin have been observed in cell lines representing different subtypes of EOC, further comprehensive comparisons regarding the actions of $\beta$-catenin among different subtypes would provide an insight into the contribution of this signaling pathway in the pathogenesis of each subtype. Also, more studies are required to further investigate the functions and mechanisms of the Wnt/ $\beta$ catenin pathway in promoting tumor angiogenesis and immune evasion.

The Wnt/ $\beta$-catenin pathway is recognized as an important target for cancer therapy and many studies have been done to investigate the potential therapeutic effects of antibodies and small molecules that target this pathway and some of them are currently in clinical trials [185-188]. However, most of these studies focus on other types of cancer, especially colon cancer. Several studies carried out on EOC cells have shown that inhibitors of this pathway strongly reduced tumor growth and metastasis [100, 189, 190]. To date, only one clinical study on Wnt targeting drugs has been reported for
EOC. In a phase $1 \mathrm{~b}$ clinical trial, ipafricept, a fusion protein that antagonizes Wnt signalling by binding Wnt ligands, was found to be well tolerated when used with standard chemotherapies [191]. Given the hyperactivation of the $\mathrm{Wnt} / \beta$-catenin pathway and its strong tumor-promoting effects in EOC, it is highly possible that inhibition of the pathway will have strong therapeutic potentials. More clinical studies should be done in EOC to explore this possibility.

\begin{abstract}
Abbreviations
ABCG2: ATP-binding cassette sub-family G member 2; AKT: RAC-alpha serine/ threonine-protein kinase; ALDH: Aldehyde dehydrogenase;

APC: Adenomatous polyposis coli; ATP: Adenosine triphosphate; bFGF: Basic fibroblast growth factors; BMI1: Polycomb complex protein BMI-1; BMP-

10: Bone morphogenetic protein-10; BRCA: Breast cancer susceptibility protein; CBL: C asitas B-lineage Lymphoma; CBP: Creb-binding protein; CCC: Clear cell carcinoma; CCNG2: Cyclin G2; CCNY: Cyclin Y; CD: Cluster of differentiation; CDK: Cyclin-dependent kinase; circRNA: Circular RNA; CK1: Casein kinase 1; C-kit: Mast/stem cell growth factor receptor Kit; CSC: Cancer stem cell; CUL4A: Cullin-4a; DACT1: Dishevelled binding agonist of $\beta$-catenin 1 or Dapper 1; DKK: Dickkopf-related protein; DVL: Dishevelled; EC: Endometrioid carcinoma; ECM: Extracellular matrix; EMT: Epithelial-toMesenchymal Transition; EOC: Epithelial ovarian cancer; EPCAM: Epithelial cell adhesion molecule; FHL2: Four and half LIM domain protein 2;

FILIP1L: Filamin A interacting protein 1-like; FN: Fibronectin; FOXA2: Forkhead box protein A2; FOXM1: Forkhead box protein M1; FOXO3: Forkhead box protein O3; FZD: Frizzled receptor; GSK3ß: Glycogen synthase kinase 3 3 ; hCTR1: Human copper transporter 1; HGSC: High-grade serous carcinoma; ICAT: $\beta$-catenin interacting protein 1; IDO: Indoleamine 2, 3-dioxygenase; IL: Interleukin; Jak: Janus kinase; JRK: Jerky protein homolog; KIAA0101: PCNAassociated factor; LGR: Leucine-rich repeat containing G protein-coupled receptor; LGSC: Low-grade serous carcinoma; IncRNA: Long non-coding RNA; LPA: Lysophosphatidic acid; LPAR: Lysophosphatidic acid receptor; LRP: Lowdensity lipoprotein receptor-related protein; MARCH7: Membrane-associated ring finger protein 7; MC: Mucinous carcinomas; miRNA: micro RNA; MMP: Matrix metalloproteinase; NANOG: Homeobox protein NANOG; OCT: Octamer-binding protein; PARP: Poly (ADP-ribose) polymerase; PDL1: Programmed cell-death ligand; PI3K: Phosphoinositide 3-kinase; PIK3R3: Phosphatidylinositol 3-kinase regulatory subunit gamma; PP2A: Protein phosphatase 2; PYGO: Pygopus; Rab14: Ras-related protein Rab-14; Rnf43: Ring finger protein 43; RSPO: R-spondin; SCF: Stem cell growth factor; SCF- $\beta$ TrCP: skp, cullin and f-box containing complex- $\beta$ transducin repeats-containing protein; SFRP: Secreted Frizzled-Related Protein; siRNA: Small interfering RNA; Skp1: S-phase kinase-associated protein 1; SNP: Single nucleotide polymorphism; SP1: Specificity protein 1; STAT: Signal transducers and activators of transcription; TCF/LEF: T cell factor/lymphoid enhancer factor; TCGA: The Cancer Genome Atlas; TET: Ten-eleven translocation methylcytosine dioxygenase; TF3: Theaflavin-3, 3'-digallate; TG2: Tissue transglutamase 2; TGF $\beta$ : Transforming growth factor beta; Th17: T helper 17 cell; TNKS: Tankyrase; Treg: Regulatory T cells; VEGF: Vascular endothelial growth factor; YY1: Ying Yang1; Znrf3: Zinc and ring finger 3
\end{abstract}

\section{Authors' contributions}

All authors contributed to the drafting and revising of the manuscript. All authors read and approved the final manuscript.

\section{Funding}

Work done in our laboratory was funded by the Canadian Institutes of Health Research (MOP-89931) and the York Research Chair Program to CP.

\section{Availability of data and materials}

$\mathrm{N} / \mathrm{A}$

\section{Ethics approval and consent to participate}

$\mathrm{N} / \mathrm{A}$

\section{Consent for publication}

N/A 


\section{Competing interests}

The authors declare that they have no competing interests

\section{Received: 30 September 2019 Accepted: 27 November 2019} Published online: 11 December 2019

\section{References}

1. Siegel RL, Miller KD, Jemal A. Cancer statistics, 2019. CA Cancer J Clin. 2019; 69(1):7-34.

2. Gilks CB, Prat J. Ovarian carcinoma pathology and genetics: recent advances. Hum Pathol. 2009;40(9):1213-23.

3. Medicine Io, National Academies of Sciences E, Medicine. Ovarian cancers: evolving paradigms in research and care. Washington, DC: The National Academies Press; 2016. 396 p

4. Howlader N, Noone AM, Krapcho M, Garshell J, Miller D, Altekruse SF, et al. National Cancer Institute SEER Cancer Statistics Review 1975-2012. Natl Cancer Inst. 2015;1975-2012. Available from: http://seer.cancer.gov/csr/1 975_2012/

5. Luvero D, Milani A, Ledermann JA. Treatment options in recurrent ovarian cancer: latest evidence and clinical potential. Ther Adv Med Oncol. 2014; 6(5):229-39

6. Coleman RL, Monk BJ, Sood AK, Herzog TJ. Latest research and treatment of advanced-stage epithelial ovarian cancer. Nat Rev Clin Oncol. 2013;10(4) 211-24.

7. Cortez AJ, Tudrej P, Kujawa KA, Lisowska KM. Advances in ovarian cancer therapy. Cancer Chemother Pharmacol. 2018;81:17-38.

8. Parkes EE, Kennedy RD. Clinical Application of Poly (ADP-Ribose) polymerase inhibitors in high-grade serous ovarian cancer. Oncologist. 2016;21:586-93.

9. Logan CY, Nusse R. The Wnt signaling pathway in development and disease. Annu Rev Cell Dev Biol. 2004;20:781-810.

10. Clevers H. Wnt/beta-catenin signaling in development and disease. Cell. 2006;127(3):469-80.

11. Polakis P. The many ways of Wnt in cancer. Curr Opin Genet Dev. 2007; 17(1):45-51.

12. Arend RC, Londono-Joshi Al, Straughn JM Jr, Buchsbaum DJ. The Wnt/betacatenin pathway in ovarian cancer: a review. Gynecol Oncol. 2013;131(3):772-9.

13. Clevers H, Nusse R. Wnt/beta-catenin signaling and disease. Cell. 2012; 149(6):1192-205.

14. Gao C, Wang Y, Broaddus R, Sun L, Xue F, Zhang W. Exon 3 mutations of CTNNB1 drive tumorigenesis: a review. Oncotarget. 2017;9(4):5492-508.

15. Pai SG, Carneiro BA, Mota JM, Costa R, Leite CA, Barroso-Sousa R, et al. Wnt/ beta-catenin pathway: modulating anticancer immune response. J Hematol Oncol. 2017:10(1):101.

16. Olsen JJ, Pohl SÖ, Deshmukh A, Visweswaran M, Ward NC, Arfuso F, et al. The role of Wnt signalling in angiogenesis. Clin Biochem Rev. 2017;38(3): $131-42$.

17. Nagaraj $A B$, Joseph $P$, Kovalenko $O$, Singh $S$, Armstrong $A$, Redline $R$, et al. Critical role of Wnt/beta-catenin signaling in driving epithelial ovarian cancer platinum resistance. Oncotarget. 2015;6(27):23720-34.

18. Tang MKS, Yue PYK, Ip PP, Huang RL, Lai HC, Cheung ANY, et al. Soluble Ecadherin promotes tumor angiogenesis and localizes to exosome surface. Nat Commun. 2018;9(1):2270

19. Cannon MJ, Ghosh D, Gujja S. Signaling circuits and regulation of immune suppression by ovarian tumor-associated macrophages. Vaccines. 2015;3(2): 448-66.

20. Wright K, Wilson P, Morland S, Campbell I, Walsh M, Hurst T, et al. betacatenin mutation and expression analysis in ovarian cancer: exon 3 mutations and nuclear translocation in $16 \%$ of endometrioid tumours. Int J Cancer. 1999;82(5):625-9.

21. Wu R, Zhai Y, Fearon ER, Cho KR. Diverse mechanisms of beta-catenin deregulation in ovarian endometrioid adenocarcinomas. Cancer Res. 2001; 61(22):8247-55.

22. Stamos JL, Weis WI. The beta-catenin destruction complex. Cold Spring Harb Perspect Biol. 2013;5(1):a007898.

23. Liu C, Li Y, Semenov M, Han C, Baeg GH, Tan Y, et al. Control of betacatenin phosphorylation/degradation by a dual-kinase mechanism. Cell. 2002;108(6):837-47.

24. Ha NC, Tonozuka T, Stamos JL, Choi HJ, Weis WI. Mechanism of phosphorylation-dependent binding of APC to beta-catenin and its role in beta-catenin degradation. Mol Cell. 2004;15(4):511-21.
25. Jho E, Lomvardas S, Costantini F. A GSK3beta phosphorylation site in axin modulates interaction with beta-catenin and Tcf-mediated gene expression. Biochem Biophys Res Commun. 1999;266(1):28-35.

26. Kim SE, Huang H, Zhao M, Zhang X, Zhang A, Semonov MV, et al. Wnt stabilization of beta-catenin reveals principles for morphogen receptorscaffold assemblies. Science. 2013;340(6134):867-70.

27. $W u$ G, Xu G, Schulman BA, Jeffrey PD, Harper JW, Pavletich NP. Structure of a beta-TrCP1-Skp1-beta-catenin complex: destruction motif binding and lysine specificity of the SCF (beta-TrCP1) ubiquitin ligase. Mol Cell. 2003; 11(6)::1445-56.

28. Tauriello DV, Jordens I, Kirchner K, Slootstra JW, Kruitwagen T, Bouwman BA, et al. Wnt/beta-catenin signaling requires interaction of the Dishevelled DEP domain and $\mathrm{C}$ terminus with a discontinuous motif in Frizzled. Proc Natl Acad Sci USA. 2012;109(14):E812-20.

29. Nusse R, Clevers H. Wnt/beta-catenin signaling, disease, and emerging therapeutic modalities. Cell. 2017;169(6):985-99.

30. Filho LB, Oshima CTF, De Oliveira Lima F, De Oliveira Costa H, De Sousa Damaão R, Gomes TS, et al. Canonical and noncanonical Wnt pathway: a comparison among normal ovary, benign ovarian tumor and ovarian cancer. Oncol Rep. 2009;21(2):313-20.

31. Gamallo C, Palacios J, Moreno G, Calvo de Mora J, Suarez A, Armas A. betacatenin expression pattern in stage I and II ovarian carcinomas : relationship with beta-catenin gene mutations, clinicopathological features, and clinical outcome. Am J Pathol. 1999;155(2):527-36.

32. Sarrio D, Moreno-Bueno G, Sanchez-Estevez C, Banon-Rodriguez I, Hernandez-Cortes G, Hardisson D, et al. Expression of cadherins and catenins correlates with distinct histologic types of ovarian carcinomas. Hum Pathol. 2006;37(8):1042-9.

33. MacDonald BT, Tamai K, He X. Wnt/beta-catenin signaling: components, mechanisms, and diseases. Dev Cell. 2009;17(1):9-26.

34. Gershoni-Baruch R, Patael Y, Dagan E, Figer A, Kasinetz L, Kadouri E, et al. Association of the I1307K APC mutation with hereditary and sporadic breast/ ovarian cancer: more questions than answers. Br J Cancer. 2000;83(2):153-5.

35. Mueller JJ, Schlappe BA, Kumar R, Olvera N, Dao F, Abu-Rustum N, et al. Massively parallel sequencing analysis of mucinous ovarian carcinomas: genomic profiling and differential diagnoses. Gynecol Oncol. 2018;150(1): $127-35$.

36. Yoshioka S, King ML, Ran S, Okuda H, MacLean JA 2nd, McAsey ME, et al. WNT7A regulates tumor growth and progression in ovarian cancer through the WNT/beta-catenin pathway. Mol Cancer Res. 2012;10(3):469-83.

37. Liu Y, Meng F, Xu Y, Yang S, Xiao M, Chen X, et al. Overexpression of Wnt7a is associated with tumor progression and unfavorable prognosis in endometrial cancer. Int J Gynecol Cancer. 2013;23(2):304-11.

38. Liu Q, Zhao Y, Xing H, Li L, Li R, Dai J, et al. The role of R-spondin 1 through activating Wnt/beta-catenin in the growth, survival and migration of ovarian cancer cells. Gene. 2019;689:124-30.

39. de Lau W, Peng WC, Gros P, Clevers H. The R-spondin/Lgr5/Rnf43 module: regulator of Wnt signal strength. Genes Dev. 2014;28(4):305-16.

40. Kim KA, Zhao J, Andarmani S, Kakitani M, Oshima T, Binnerts ME, et al. RSpondin proteins: a novel link to beta-catenin activation. Cell Cycle. 2006; 5(1):23-6.

41. Kuchenbaecker KB, Ramus SJ, Tyrer J, Lee A, Shen HC, Beesley J, et al. Identification of six new susceptibility loci for invasive epithelial ovarian cancer. Nat Genet. 2015;47(2):164-71.

42. Schindler AJ, Watanabe A, Howell SB. LGR5 and LGR6 in stem cell biology and ovarian cancer. Oncotarget. 2018;9(1):1346-55.

43. Ruan X, Liu A, Zhong M, Wei J, Zhang W, Rong Y, et al. Silencing LGR6 attenuates stemness and chemoresistance via inhibiting Wnt/beta-catenin signaling in ovarian cancer. Mol Ther Oncolytics. 2019;14:94-106.

44. Cruciat CM, Niehrs C. Secreted and transmembrane Wnt inhibitors and activators. Cold Spring Harb Perspect Biol. 2013;5(3):a015081.

45. Barbolina MV, Liu Y, Gurler H, Kim M, Kajdacsy-Balla AA, Rooper L, et al. Matrix rigidity activates Wnt signaling through down-regulation of Dickkopf1 protein. J Biol Chem. 2013;288(1):141-51.

46. Zhu J, Zhang S, Gu L, Di W. Epigenetic silencing of DKK2 and Wnt signal pathway components in human ovarian carcinoma. Carcinogenesis. 2012; 33(12):2334-43.

47. Jacob F, Ukegjini K, Nixdorf S, Ford CE, Olivier J, Caduff R, et al. Loss of secreted frizzled-related protein 4 correlates with an aggressive phenotype and predicts poor outcome in ovarian cancer patients. PLoS One. 2012;7(2):e31885. 
48. Saran U, Arfuso F, Zeps N, Dharmarajan A. Secreted frizzled-related protein 4 expression is positively associated with responsiveness to Cisplatin of ovarian cancer cell lines in vitro and with lower tumour grade in mucinous ovarian cancers. BMC Cell Biol. 2012;13(1):25.

49. Ford CE, Jary E, Ma SS, Nixdorf S, Heinzelmann-Schwarz VA, Ward RL. The Wnt gatekeeper SFRP4 modulates EMT, cell migration and downstream Wnt signalling in serous ovarian cancer cells. PLoS One. 2013:8(1):e54362.

50. Duan H, Yan Z, Chen W, Wu Y, Han J, Guo H, et al. TET1 inhibits EMT of ovarian cancer cells through activating Wnt/beta-catenin signaling inhibitors DKK1 and SFRP2. Gynecol Oncol. 2017;147(2):408-17.

51. Kohli RM, Zhang Y. TET enzymes, TDG and the dynamics of DNA demethylation. Nature. 2013;502(7472):472-9.

52. Xu G, Bernaudo S, Fu G, Lee DY, Yang BB, Peng C. Cyclin G2 is degraded through the ubiquitin-proteasome pathway and mediates the antiproliferative effect of activin receptor-like kinase 7. Mol Biol Cell. 2008; 19(11):4968-79.

53. Bernaudo S, Salem M, Qi X, Zhou W, Zhang C, Yang W, et al. Cyclin G2 inhibits epithelial-to-mesenchymal transition by disrupting Wnt/beta-catenin signaling. Oncogene. 2016;35(36):4816-27.

54. Gao J, Zhao C, Liu Q, Hou X, Li S, Xing X, et al. Cyclin G2 suppresses Wnt/ beta-catenin signaling and inhibits gastric cancer cell growth and migration through Dapper1. J Exp Clin Cancer Res. 2018;37(1):317.

55. Ma B, Liu B, Cao W, Gao C, Qi Z, Ning Y, et al. The Wnt signaling antagonist dapper1 accelerates dishevelled2 degradation via promoting its ubiquitination and aggregate-induced autophagy. J Biol Chem. 2015; 290(19):12346-54.

56. Teran E, Branscomb AD, Seeling JM. Dpr acts as a molecular switch, inhibiting Wnt signaling when unphosphorylated, but promoting Wnt signaling when phosphorylated by casein kinase I $\delta / \varepsilon$. PLOS ONE. 2009; 4(5):e5522.

57. Li RN, Liu B, Li XM, Hou LS, Mu XL, Wang H, et al. DACT1 Overexpression in type I ovarian cancer inhibits malignant expansion and cis-platinum resistance by modulating canonical Wnt signalling and autophagy. Sci Rep. 2017;7(1):9285

58. Liu H, Shi H, Fan Q, Sun X. Cyclin Y regulates the proliferation, migration, and invasion of ovarian cancer cells via Wnt signaling pathway. Tumor Biol. 2016;37(8):10161-75.

59. Davidson G, Niehrs C. Emerging links between CDK cell cycle regulators and Wnt signaling. Trends Cell Biol. 2010;20(8):453-60.

60. Ou-Yang J, Huang LH, Sun XX. Cyclin-dependent kinase 14 promotes cell proliferation, migration and invasion in ovarian cancer by inhibiting Wnt signaling pathway. Gynecol Obstet Invest. 2017;82(3):230-9.

61. Rask K, Nilsson A, Brannstrom M, Carlsson P, Hellberg P, Janson PO, et al. Wnt-signalling pathway in ovarian epithelial tumours: increased expression of beta-catenin and GSK3beta. Br J Cancer. 2003;89(7):1298-304

62. Shen C, Sheng Q, Zhang X, Fu Y, Zhu K. Hypermethylated APC in serous carcinoma based on a meta-analysis of ovarian cancer. J Ovarian Res. 2016;9(1):60.

63. Tam KF, Liu WWS, Liu SS, Tsang PCK, Cheung ANY, Yip AMW, et al. Methylation profile in benign, borderline and malignant ovarian tumors. J Cancer Res Clin Oncol. 2007;133(5):331-41.

64. Ibanez de Caceres I, Battagli C, Esteller M, Herman JG, Dulaimi E, Edelson MI, et al. Tumor cell-specific BRCA1 and RASSF1A hypermethylation in serum, plasma, and peritoneal fluid from ovarian cancer patients. Cancer Res. 2004; 64(18):6476-81.

65. Haikarainen T, Krauss S, Lehtio L. Tankyrases: structure, function and therapeutic implications in cancer. Curr Pharm Des. 2014;20(41):6472-88.

66. Bao R, Christova T, Song S, Angers S, Yan X, Attisano L. Inhibition of tankyrases induces Axin stabilization and blocks Wnt signalling in breast cancer cells. PLoS One. 2012;7(11):e48670.

67. Yang HY, Shen JX, Wang Y, Liu Y, Shen DY, Quan S. Tankyrase promotes aerobic glycolysis and proliferation of ovarian cancer through activation of Wnt/beta-catenin signaling. Biomed Res Int. 2019;2019: 2686340.

68. Hou R, Jiang L, Yang Z, Wang S, Liu Q. Rab14 is overexpressed in ovarian cancers and promotes ovarian cancer proliferation through Wht pathway. Tumor Biol. 2016;37(12):16005-13.

69. Kwon M, Kim J-H, Rybak Y, Luna A, Choi CH, Chung J-Y, et al. Reduced expression of FILIP1L, a novel WNT pathway inhibitor, is associated with poor survival, progression and chemoresistance in ovarian cancer. Oncotarget. 2016;7(47):77052-70.
70. Luo J. Glycogen synthase kinase 3beta (GSK3beta) in tumorigenesis and cancer chemotherapy. Cancer Lett. 2009;273(2):194-200.

71. Yan X, Lyu T, Jia N, Yu Y, Hua K, Feng W. Huaier aqueous extract inhibits ovarian cancer cell motility via the AKT/GSK3beta/beta-catenin pathway. PLoS One. 2013;8(5):e63731.

72. Kwon M, Lee SJ, Wang Y, Rybak Y, Luna A, Reddy S, et al. Filamin A interacting protein 1-like inhibits WNT signaling and MMP expression to suppress cancer cell invasion and metastasis. Int J Cancer. 2014;135(1):48-60.

73. Park YL, Park SY, Lee SH, Kim RB, Kim JK, Rew SY, et al. Filamin A interacting protein 1-like expression inhibits progression in colorectal cancer. Oncotarget. 2016;7(44):72229-41.

74. Takai Y, Sasaki T, Matozaki T. Small GTP-binding proteins. Physiol Rev. 2001; 81(1):153-208

75. Huber AH, Weis WI. The structure of the beta-catenin/E-cadherin complex and the molecular basis of diverse ligand recognition by beta-catenin. Cell. 2001;105(3):391-402.

76. Xu W, Kimelman D. Mechanistic insights from structural studies of betacatenin and its binding partners. J Cell Sci. 2007;120(19):3337-44.

77. Brembeck FH, Rosario M, Birchmeier W. Balancing cell adhesion and Wnt signaling, the key role of beta-catenin. Curr Opin Genet Dev. 2006;16(1):51-9.

78. Kajiguchi T, Katsumi A, Tanizaki R, Kiyoi H, Naoe T. Y654 of beta-catenin is essential for FLT3/ITD-related tyrosine phosphorylation and nuclear localization of beta-catenin. Eur J Haematol. 2012:88(4):314-20.

79. Satpathy M, Cao L, Pincheira R, Emerson R, Bigsby R, Nakshatri H, et al. Enhanced peritoneal ovarian tumor dissemination by tissue transglutaminase. Cancer Res. 2007;67(15):7192-202.

80. Condello S, Cao L, Matei D. Tissue transglutaminase regulates beta-catenin signaling through a c-Src-dependent mechanism. Faseb J. 2013;27(8):3100-12.

81. Burkhalter RJ, Westfall SD, Liu Y, Stack MS. Lysophosphatidic acid initiates epithelial to mesenchymal transition and Induces beta-Catenin-mediated transcription in epithelial ovarian carcinoma. J Biol Chem. 2015;290(36): 22143-54.

82. Chan DW, Mak CSL, Leung THY, Chan KKL, Ngan HYS. Down-regulation of Sox7 is associated with aberrant activation of Wnt/beta-catenin signaling in endometrial cancer. Oncotarget. 2012;3(12):1546-56.

83. Liu H, Yan ZQ, Li B, Yin SY, Sun Q, Kou JJ, et al. Reduced expression of SOX7 in ovarian cancer: a novel tumor suppressor through the Wnt/beta-catenin signaling pathway. J Ovarian Res. 2014;7:87.

84. Du L, Qian X, Dai C, Wang L, Huang D, Wang S, et al. Screening the molecular targets of ovarian cancer based on bioinformatics analysis. Tumori. 2015;101(4):384-9.

85. Popadiuk CM, Xiong J, Wells MG, Andrews PG, Dankwa K, Hirasawa K, et al. Antisense suppression of pygopus2 results in growth arrest of epithelial ovarian cancer. Clin Cancer Res. 2006;12(7 Pt 1):2216-23.

86. Benchabane H, Xin N, Tian A, Hafler BP, Nguyen K, Ahmed A, et al. Jerky/ Earthbound facilitates cell-specific Wnt/Wingless signalling by modulating beta-catenin-TCF activity. EMBO J. 2011;30(8):1444-58.

87. Pangon L, Ng I, Giry-Laterriere M, Currey N, Morgan A, Benthani F, et al. JRK is a positive regulator of beta-catenin transcriptional activity commonly overexpressed in colon, breast and ovarian cancer. Oncogene. 2016;35(22):2834-41.

88. Tassi RA, Todeschini P, Siegel ER, Calza S, Cappella P, Ardighieri L, et al. FOXM1 expression is significantly associated with chemotherapy resistance and adverse prognosis in non-serous epithelial ovarian cancer patients. J Exp Clin Cancer Res. 2017;36(1):63.

89. Zhao F, Siu MKY, Jiang L, Tam KF, Ngan HYS, Le XF, et al. Overexpression of forkhead box protein M1 (FOXM1) in ovarian cancer correlates with poor patient survival and contributes to paclitaxel resistance. PLoS One. 2014; 9(11):e113478

90. Wen N, Wang Y, Wen L, Zhao S-H, Ai Z-H, Wang Y, et al. Overexpression of FOXM1 predicts poor prognosis and promotes cancer cell proliferation, migration and invasion in epithelial ovarian cancer. J Transl Med. 2014;12:134

91. Chiu WT, Huang YF, Tsai HY, Chen CC, Chang CH, Huang SC, et al. FOXM1 confers to epithelial-mesenchymal transition, stemness and chemoresistance in epithelial ovarian carcinoma cells. Oncotarget. 2015;6(4):2349-65.

92. Pratheeshkumar P, Divya SP, Parvathareddy SK, Alhoshani NM, Al-Badawi IA, Tulbah A, et al. FoxM1 and beta-catenin predicts aggressiveness in Middle Eastern ovarian cancer and their co-targeting impairs the growth of ovarian cancer cells. Oncotarget. 2017;9(3):3590-604.

93. Zhang N, Wei P, Gong A, Chiu WT, Te Lee H, Colman H, et al. FoxM1 promotes beta-catenin nuclear localization and controls Wnt target-gene expression and glioma tumorigenesis. Cancer Cell. 2011;20(4):427-42. 
94. Zhan L, Li J, Wei B. Long non-coding RNAs in ovarian cancer. J Exp Clin Cancer Res. 2018;37(1):120

95. Deb B, Uddin A, Chakraborty S. miRNAs and ovarian cancer: an overview. J Cell Physiol. 2018;233(5):3846-54.

96. O'Brien J, Hayder H, Zayed Y, Peng C. Overview of MicroRNA biogenesis, mechanisms of actions, and circulation. Front Endocrinol. 2018:9:402.

97. Du WW, Zhang C, Yang W, Yong T, Awan FM, Yang BB. Identifying and characterizing circRNA-protein interaction. Theranostics. 2017;7(17):4183.

98. Zhang LY, Chen Y, Jia J, Zhu X, He Y, Wu LM. MiR-27a promotes EMT in ovarian cancer through active Wnt/beta-catenin signalling by targeting FOXO1. Cancer Biomark. 2019;24(1):31-42.

99. Wu G, Cao L, Zhu J, Tan Z, Tang M, Li Z, et al. Loss of RBMS3 confers platinum resistance in epithelial ovarian cancer via activation of miR-1265p/beta-catenin/CBP signaling. Clin Cancer Res. 2019;25(3):1022-35.

100. Chen MW, Yang ST, Chien MH, Hua KT, Wu CJ, Hsiao SM, et al. The STAT3miRNA-92-Wnt signaling pathway regulates spheroid formation and malignant progression in ovarian cancer. Cancer Res. 2017;77(8):1955-67.

101. Hou R, Yang Z, Wang S, Chu D, Liu Q, Liu J, et al. miR-762 can negatively regulate menin in ovarian cancer. Onco Targets Ther. 2017;10:2127-37.

102. Zou D, Wang D, Li R, Tang Y, Yuan L, Long X, et al. MiR-197 induces Taxol resistance in human ovarian cancer cells by regulating NLK. Tumor Biol. 2015;36(9):6725-32.

103. Ying $X$, Li-ya $Q$, Feng Z, Yin W, Ji-hong L. MiR-939 promotes the proliferation of human ovarian cancer cells by repressing APC2 expression. Biomed Pharmacother. 2015;71:64-9.

104. Wu G, Liu A, Zhu J, Lei F, Wu S, Zhang X, et al. MiR-1207 overexpression promotes cancer stem cell-like traits in ovarian cancer by activating the Wnt/beta-catenin signaling pathway. Oncotarget. 2015;6(30):28882-94.

105. Li N, Yang L, Sun Y, Wu X. MicroRNA-16 inhibits migration and invasion via regulation of the Wnt/beta-catenin signaling pathway in ovarian cancer. Oncol Lett. 2019;17(3):2631-8.

106. Huang Z, Li Q, Luo K, Zhang Q, Geng J, Zhou X, et al. miR-340-FHL2 axis inhibits cell growth and metastasis in ovarian cancer. Cell Death Dis. 2019; 10(5):372.

107. Xiao S, Li Y, Pan Q, Ye M, He S, Tian Q, et al. MiR-34c/SOX9 axis regulates the chemoresistance of ovarian cancer cell to cisplatin-based chemotherapy. J Cell Biochem. 2019;120(3):2940-53.

108. Yu R, Cai L, Chi Y, Ding X, Wu X. miR-377 targets CUL4A and regulates metastatic capability in ovarian cancer. Int J Mol Med. 2018;41(6):3147-56.

109. Chen Q, Zhang J, He Y, Wang Y. hsa_circ_0061140 knockdown reverses FOXM1-mediated cell growth and metastasis in ovarian cancer through miR-370 sponge activity. Mol Ther Nucleic Acids. 2018;13:55-63.

110. Liu Y, Lin J, Zhai S, Sun C, Xu C, Zhou H, et al. MicroRNA-214 suppresses ovarian cancer by targeting beta-catenin. Cell Physiol Biochem. 2018;45(4): 1654-62.

111. Wei C, Zhang X, He S, Liu B, Han H, Sun X. MicroRNA-219-5p inhibits the proliferation, migration, and invasion of epithelial ovarian cancer cells by targeting the Twist/Wnt/beta-catenin signaling pathway. Gene. 2017;637: 25-32.

112. Cao Y, Shi H, Ren F, Jia Y, Zhang R. Long non-coding RNA CCAT1 promotes metastasis and poor prognosis in epithelial ovarian cancer. Exp Cell Res. 2017;359(1):185-94.

113. Zhang Y, Dun Y, Zhou S, Huang X-H. LncRNA HOXD-AS1 promotes epithelial ovarian cancer cells proliferation and invasion by targeting miR133a-3p and activating Wnt/beta-catenin signaling pathway. Biomed Pharmacother. 2017;96:1216-21.

114. Chen H, Xia B, Liu T, Lin M, Lou G. KIAA0101, a target gene of miR-429, enhances migration and chemoresistance of epithelial ovarian cancer cells. Cancer Cell Int. 2016;16:74.

115. Xia B, Li H, Yang S, Liu T, Lou G. MiR-381 inhibits epithelial ovarian cancer malignancy via YY1 suppression. Tumor Biol. 2016;37(7):9157-67.

116. MacLean JA, King ML, Okuda H, Hayashi K. WNT7A regulation by miR-15b in ovarian cancer. PLoS One. 2016;11(5):e0156109.

117. Hu J, Meng Y, Yu T, Hu L, Mao M. Ubiquitin E3 ligase MARCH7 promotes ovarian tumor growth. Oncotarget. 2015;6(14):12174-87.

118. Zheng HB, Zheng XG, Liu BP. MiRNA-101 inhibits ovarian cancer cells proliferation and invasion by down-regulating expression of SOCS-2. Int J Clin Exp Med. 2015;8(11):20263-70.

119. Guo F, Cogdell D, Hu L, Yang D, Sood AK, Xue F, et al. MiR-101 suppresses the epithelial-to-mesenchymal transition by targeting ZEB1 and ZEB2 in ovarian carcinoma. Oncol Rep. 2014;31(5):2021-8.
120. Wang B, Liu M, Zhuang R, Jiang J, Gao J, Wang H, et al. Long non-coding RNA CCAT2 promotes epithelial-mesenchymal transition involving Wnt/ beta-catenin pathway in epithelial ovarian carcinoma cells. Oncol Lett. 2018; 15(3):3369-75.

121. He S, Zhao Y, Wang X, Deng Y, Wan Z, Yao S, et al. Up-regulation of long non-coding RNA SNHG20 promotes ovarian cancer progression via Wnt/ beta-catenin signaling. Biosci Rep. 2018;38(1):BSR20170681.

122. Guo C, Wang X, Chen L-P, Li M, Li M, Hu Y-H, et al. Long non-coding RNA MALAT1 regulates ovarian cancer cell proliferation, migration and apoptosis through Wnt/beta-catenin signaling pathway. Eur Rev Med Pharmacol Sci. 2018;22(12):3703-12

123. Lou Y, Jiang H, Cui Z, Wang L, Wang $X$, Tian T. Linc-ROR induces epithelialto-mesenchymal transition in ovarian cancer by increasing Wnt/betacatenin signaling. Oncotarget. 2017;8(41):69983-94.

124. Li J, Yang S, Su N, Wang Y, Yu J, Qiu H, et al. Overexpression of long noncoding RNA HOTAIR leads to chemoresistance by activating the Wnt/betacatenin pathway in human ovarian cancer. Tumor Biol. 2016;37(2):2057-65.

125. Hu J, Wang L, Chen J, Gao H, Zhao W, Huang Y, et al. The circular RNA circITCH suppresses ovarian carcinoma progression through targeting miR-145/ RASA1 signaling. Biochem Biophys Res Commun. 2018;505(1):222-8.

126. Salem M, O'Brien JA, Bernaudo S, Shawer H, Ye G, Brkic J, et al. miR-590-3p promotes ovarian cancer growth and metastasis via a Novel FOXA2Versican pathway. Cancer Res. 2018;78(15):4175-90.

127. Salem M, Shan Y, Bernaudo S, Peng C. miR-590-3p targets cyclin G2 and FOXO3 to promote ovarian cancer cell proliferation, invasion, and spheroid formation. Int J Mol Sci. 2019;20(8):1810.

128. Fu G, Peng C. Nodal enhances the activity of FoxO3a and its synergistic interaction with Smads to regulate cyclin G2 transcription in ovarian cancer cells. Oncogene. 2011;30(37):3953-66.

129. Kim B, Song TY, Jung KY, Kim SG, Cho EJ. Direct interaction of menin leads to ubiquitin-proteasomal degradation of beta-catenin. Biochem Biophys Res Commun. 2017:492(1):128-34.

130. Cao Y, Liu R, Jiang X, Lu J, Jiang J, Zhang C, et al. Nuclear-cytoplasmic shuttling of menin regulates nuclear translocation of beta-catenin. Mol Cell Biol. 2009;29(20):5477-87.

131. Dong S, Wang R, Wang H, Ding Q, Zhou X, Wang J, et al. HOXD-AS promotes the epithelial to mesenchymal transition of ovarian cancer cells by regulating miR-186-5p and PIK3R3. J Exp Clin Cancer Res. 2019:38(1):110.

132. Jones DZ, Schmidt ML, Suman S, Hobbing KR, Barve SS, Gobejishvili L, et al. Micro-RNA-186-5p inhibition attenuates proliferation, anchorage independent growth and invasion in metastatic prostate cancer cells. BMC Cancer. 2018;18(1):421.

133. Zhu Q, Lu G, Luo Z, Gui F, Wu J, Zhang D, et al. CircRNA circ_0067934 promotes tumor growth and metastasis in hepatocellular carcinoma through regulation of miR-1324/FZD5/Wnt/beta-catenin axis. Biochem Biophys Res Commun. 2018;497(2):626-32.

134. Wu Z, Shi W, Jiang C. Overexpressing circular RNA hsa_circ_0002052 impairs osteosarcoma progression via inhibiting Wnt/beta-catenin pathway by regulating miR-1205/APC2 axis. Biochem Biophys Res Commun. 2018;502(4): 465-71.

135. Chen Z, Duan X. hsa_circ 0000177-miR-638-FZD7-Wnt Signaling Cascade Contributes to the Malignant Behaviors in Glioma. DNA Cell Biol. 2018;37(9): 791-7.

136. Yang F, Fang E, Mei H, Chen Y, Li H, Li D, et al. Cis-acting circ-CTNNB1 promotes beta-catenin signaling and cancer progression via DDX3mediated transactivation of YY1. Cancer Res. 2019;79(3):557-71.

137. Huang G, Zhu H, Shi Y, Wu W, Cai H, Chen X. cir-ITCH plays an inhibitory role in colorectal cancer by regulating the Wnt/beta-catenin pathway. PLoS One. 2015:10(6):e0131225.

138. Wan L, Zhang L, Fan K, Cheng ZX, Sun QC, Wang JJ. Circular RNA-ITCH suppresses lung cancer proliferation via inhibiting the Wnt/beta-catenin pathway. Biomed Res Int. 2016:2016:1579490.

139. Wang M, Chen B, Ru Z, Cong L. CircRNA circ-ITCH suppresses papillary thyroid cancer progression through miR-22-3p/CBL/beta-catenin pathway. Biochem Biophys Res Commun. 2018;504(1):283-8.

140. Ahmed N, Abubaker K, Findlay JK. Ovarian cancer stem cells: molecular concepts and relevance as therapeutic targets. Mol Aspects Med. 2014;39: $110-25$.

141. Wang X, Wang H, Xu B, Jiang D, Huang S, Yu H, et al. Depletion of H3K79 methyltransferase Dot1 $\mathrm{L}$ promotes cell invasion and cancer stem-like cell property in ovarian cancer. Am J Transl Res. 2019;11(2):1145-53. 
142. Parte SC, Batra SK, Kakar SS. Characterization of stem cell and cancer stem cell populations in ovary and ovarian tumors. J Ovarian Res. 2018; 11(1):69.

143. Silva IA, Bai S, McLean K, Yang K, Griffith K, Thomas D, et al. Aldehyde dehydrogenase in combination with CD133 defines angiogenic ovarian cancer stem cells that portend poor patient survival. Cancer Res. 2011; 71(11):3991-4001.

144. Beck B, Blanpain C. Unravelling cancer stem cell potential. Nat Rev Cancer. 2013;13(10):727-38.

145. Kang HG, Kim DH, Kim SJ, Cho Y, Jung J, Jang W, et al. Galectin-3 supports stemness in ovarian cancer stem cells by activation of the Notch1 intracellular domain. Oncotarget. 2016;7(42):68229-41.

146. Wang YC, Te Yo Y, Lee HY, Liao YP, Chao TK, Su PH, et al. ALDH1bright epithelial ovarian cancer cells are associated with CD44 expression, drug resistance, and poor clinical outcome. Am J Pathol. 2012;180(3):1159-69.

147. Burgos-Ojeda D, Rueda BR, Buckanovich RJ. Ovarian cancer stem cell markers: prognostic and therapeutic implications. Cancer Lett. 2012;322(1):1-7.

148. Garson K, Vanderhyden BC. Epithelial ovarian cancer stem cells: underlying complexity of a simple paradigm. Reproduction. 2015;149(2):R59-70.

149. Ffrench B, Gasch C, O'Leary JJ, Gallagher MF. Developing ovarian cancer stem cell models: laying the pipeline from discovery to clinical intervention. Mol Cancer. 2014;13(262):1-15.

150. Shah MM, Landen CN. Ovarian cancer stem cells: are they real and why are they important? Gynecol Oncol. 2014;132(2):483-9.

151. Condello S, Morgan CA, Nagdas S, Cao L, Turek J, Hurley TD, et al. betaCatenin-regulated ALDH1A1 is a target in ovarian cancer spheroids. Oncogene. 2015;34(18):2297-308

152. Sun $Y$, Jia $X$, Wu X. High expressions of Lgr5 and ALDH1 in primary epithelial ovarian cancer correlate with advanced tumor stage and grade as well as poor prognosis of the patients. Gynecol Obstet Invest. 2016;81(2): 162-8.

153. Flesken-Nikitin A, Hwang Cl, Cheng CY, Michurina TV, Enikolopov G, Nikitin AY. Ovarian surface epithelium at the junction area contains a cancer-prone stem cell niche. Nature. 2013;495(7440):241-5.

154. Pan H, Kim E, Rankin GO, Rojanasakul Y, Tu Y, Chen YC. Theaflavin-3, 3'digallate inhibits ovarian cancer stem cells via suppressing Wnt/betaCatenin signaling pathway. J Funct Foods. 2018;50:1-7.

155. Deng S, Wong CKC, Lai HC, Wong AST. Ginsenoside-Rb1 targets chemotherapy-resistant ovarian cancer stem cells via simultaneous inhibition of Wnt/beta-catenin signaling and epithelial-to-mesenchymal transition. Oncotarget. 2017;8(16):25897-914.

156. Rosen DG, Mercado-Uribe I, Yang G, Bast RC Jr, Amin HM, Lai R, et al. The role of constitutively active signal transducer and activator of transcription 3 in ovarian tumorigenesis and prognosis. Cancer. 2006;107(11):2730-40.

157. Mariya T, Hirohashi Y, Torigoe T, Tabuchi Y, Asano T, Saijo H, et al. Matrix metalloproteinase-10 regulates stemness of ovarian cancer stem-like cells by activation of canonical Wnt signaling and can be a target of chemotherapyresistant ovarian cancer. Oncotarget. 2016;7(18):26806-22.

158. Wang J, Zhou D, He X, Wang Y, Hu W, Jiang $L$, et al. Effect of downregulated beta-catenin on cell proliferative activity, the sensitivity to chemotherapy drug and tumorigenicity of ovarian cancer cells. Cell Mol Biol (Noisy-le-grand) 2011;57 Suppl:Ol1606-13.

159. Chau WK, Ip CK, Mak AS, Lai HC, Wong AS. c-Kit mediates chemoresistance and tumor-initiating capacity of ovarian cancer cells through activation of Wnt/beta-catenin-ATP-binding cassette G2 signaling. Oncogene. 2013;32(22): 2767-81.

160. Yamamoto TM, McMellen A, Watson ZL, Aguilera J, Ferguson R,

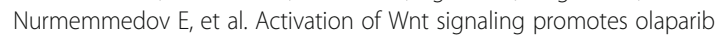
resistant ovarian cancer. Mol Carcinog. 2019;58(10):1770-82.

161. Kalluri R, Weinberg RA. The basics of epithelial-mesenchymal transition. J Clin Invest. 2009;119(6):1420-8.

162. Al-Alem L, Curry TE Jr. Ovarian cancer: involvement of the matrix metalloproteinases. Reproduction. 2015;150(2):R55-64.

163. Davidson B, Tropé CG, Reich R. Epithelial-mesenchymal transition in ovarian carcinoma. Front Oncol. 2012;2:33.

164. Kenny HA, Lengyel E. MMP-2 functions as an early response protein in ovarian cancer metastasis. Cell Cycle. 2009;8(5):683-8.

165. Wang WS, Yang XS, Xia M, Jiang HY, Hou JQ. Silencing of twist expression by RNA interference suppresses epithelial-mesenchymal transition, invasion, and metastasis of ovarian cancer. Asian Pac J Cancer Prev. 2013;13(9):4435-9.
166. Sun J, Yang X, Zhang R, Liu S, Gan X, Xi X, et al. GOLPH3 induces epithelialmesenchymal transition via Wnt/beta-catenin signaling pathway in epithelial ovarian cancer. Cancer Med. 2017;6(4):834-44.

167. Russell H, Pranjol MZI. Transcription factors controlling E-cadherin downregulation in ovarian cancer. Biosci Horizons. 2018;11.

168. Stemmer V, de Craene B, Berx G, Behrens J. Snail promotes Wnt target gene expression and interacts with beta-catenin. Oncogene. 2008;27(37): 5075-80.

169. Curry TE Jr, Osteen KG. The matrix metalloproteinase system: changes, regulation, and impact throughout the ovarian and uterine reproductive cycle. Endocr Rev. 2003;24(4):428-65.

170. Wu B, Crampton SP, Hughes CCW. Wnt signaling induces matrix metalloproteinase expression and regulates T cell transmigration. Immunity. 2007;26(2):227-39.

171. Wang $L$, Jin $X$, Lin D, Liu Z, Zhang $X$, Lu Y, et al. Clinicopathologic significance of claudin-6, occludin, and matrix metalloproteinases -2 expression in ovarian carcinoma. Diagn Pathol. 2013;8:190.

172. Zohny SF, Fayed ST. Clinical utility of circulating matrix metalloproteinase-7 (MMP-7), CC chemokine ligand 18 (CCL18) and CC chemokine ligand 11 (CCL11) as markers for diagnosis of epithelial ovarian cancer. Med Oncol. 2010:27(4):1246-53.

173. Hu X, Li D, Zhang W, Zhou J, Tang B, Li L. Matrix metalloproteinase-9 expression correlates with prognosis and involved in ovarian cancer cell invasion. Arch Gynecol Obstet. 2012;286(6):1537-43.

174. Li LN, Zhou X, Gu Y, Yan J. Prognostic value of MMP-9 in ovarian cancer: a meta-analysis. Asian Pac J Cancer Prev. 2013;14(7):4107-13.

175. Wang FQ, So J, Reierstad S, Fishman DA. Matrilysin (MMP-7) promotes invasion of ovarian cancer cells by activation of progelatinase. Int J Cancer. 2005:114(1):19-31.

176. To SKY, Mak ASC, Eva Fung YM, Che CM, Li SS, Deng W, et al. beta-catenin downregulates Dicer to promote ovarian cancer metastasis. Oncogene. 2017;36(43):5927-38

177. Chung AS, Ferrara N. Developmental and pathological angiogenesis. Annu Rev Cell Dev Biol. 2011;27:563-84

178. Rapp J, Jaromi L, Kvell K, Miskei G, Pongracz JE. WNT signaling - lung cancer is no exception. Respir Res. 2017:18(1):167.

179. Curiel TJ, Coukos G, Zou L, Alvarez X, Cheng P, Mottram P, et al. Specific recruitment of regulatory $T$ cells in ovarian carcinoma fosters immune privilege and predicts reduced survival. Nat Med. 2004;10(9): 942-9.

180. Hamanishi J, Mandai M, Iwasaki M, Okazaki T, Tanaka Y, Yamaguchi K, et al. Programmed cell death 1 ligand 1 and tumor-infiltrating CD8+ T lymphocytes are prognostic factors of human ovarian cancer. Proc Natl Acad Sci. 2007;104(9):3360-5.

181. Goyne HE, Stone PJB, Burnett AF, Cannon MJ. Ovarian tumor ascites CD14+ cells suppress dendritic cell-activated CD4+ T-cell responses through IL-10 secretion and indoleamine 2,3-dioxygenase. J Immunother. 2014;37(3):163-9.

182. Okamoto A, Nikaido T, Ochiai K, Takakura S, Saito M, Aoki Y, et al. Indoleamine 2,3-dioxygenase serves as a marker of poor prognosis in gene expression profiles of serous ovarian cancer cells. Clin Cancer Res. 2005; 11(16):6030-9.

183. Inaba T, Ino K, Kajiyama H, Yamamoto E, Shibata K, Nawa A, et al. Role of the immunosuppressive enzyme indoleamine 2,3-dioxygenase in the progression of ovarian carcinoma. Gynecol Oncol. 2009;115(2):185-92.

184. Soichot M, Hennart B, Al Saabi A, Leloire A, Froguel P, Levy-Marchal C, et al. Identification of a variable number of tandem repeats polymorphism and characterization of LEF-1 response elements in the promoter of the IDO1 gene. PLoS One. 2011;6(9):e25470.

185. Kahn M. Can we safely target the WNT pathway? Nat Rev Drug Discov. 2014;13(7):513-32

186. Cheng X, Xu X, Chen D, Zhao F, Wang W. Therapeutic potential of targeting the Wnt/beta-catenin signaling pathway in colorectal cancer. Biomed Pharmacother. 2019;110:473-81.

187. Harb J, Lin PJ, Hao J. Recent development of Wnt signaling pathway inhibitors for cancer therapeutics. Curr Oncol Rep. 2019;21(2):12.

188. Goldsberry WN, Londono A, Randall TD, Norian LA, Arend RC. A review of the role of Wnt in cancer immunomodulation. Cancers. 2019;11(6).

189. Zhang C, Zhang Z, Zhang S, Wang W, Hu P. Targeting of Wnt/beta-catenin by anthelmintic drug pyrvinium enhances sensitivity of ovarian cancer cells to chemotherapy. Med Sci Monit. 2017;23:266-75. 
190. Raghavan S, Mehta P, Xie Y, Lei YL, Mehta G. Ovarian cancer stem cells and macrophages reciprocally interact through the WNT pathway to promote pro-tumoral and malignant phenotypes in 3D engineered microenvironments. J Immunother Cancer. 2019:7(1):190.

191. Moore KN, Gunderson CC, Sabbatini P, McMeekin DS, Mantia-Smaldone G, Burger RA, et al. A phase 1b dose escalation study of ipafricept (OMP54F28) in combination with paclitaxel and carboplatin in patients with recurrent platinum-sensitive ovarian cancer. Gynecol Oncol. 2019;154(2):294-301.

\section{Publisher's Note}

Springer Nature remains neutral with regard to jurisdictional claims in published maps and institutional affiliations.

Ready to submit your research? Choose BMC and benefit from:

- fast, convenient online submission

- thorough peer review by experienced researchers in your field

- rapid publication on acceptance

- support for research data, including large and complex data types

- gold Open Access which fosters wider collaboration and increased citations

- maximum visibility for your research: over $100 \mathrm{M}$ website views per year

At $\mathrm{BMC}$, research is always in progress.

Learn more biomedcentral.com/submissions 